Research Article

\title{
Effects of LOX Particle Diameter on Combustion Characteristics of a Gas-Liquid Pintle Rocket Engine
}

\author{
Xuan Jin $(\mathbb{D}$, Chibing Shen $(\mathbb{D}$, Rui Zhou, and Xinxin Fang \\ Science and Technology on Scramjet Laboratory, College of Aerospace Science and Engineering, National University of \\ Defense Technology, Changsha 410073, China \\ Correspondence should be addressed to Chibing Shen; cbshen@nudt.edu.cn
}

Received 12 July 2020; Revised 25 July 2020; Accepted 3 August 2020; Published 15 September 2020

Academic Editor: Jing-Lei Xu

Copyright (C) 2020 Xuan Jin et al. This is an open access article distributed under the Creative Commons Attribution License, which permits unrestricted use, distribution, and reproduction in any medium, provided the original work is properly cited.

\begin{abstract}
$\mathrm{LOX} / \mathrm{GCH}_{4}$ pintle injector is suitable for variable-thrust liquid rocket engines. In order to provide a reference for the later design and experiments, three-dimensional numerical simulations with the Euler-Lagrange method were performed to study the effect of the initial particle diameter on the combustion characteristics of a $\mathrm{LOX} / \mathrm{GCH}_{4}$ pintle rocket engine. Numerical results show that, as the momentum ratio between the radial LOX jet and the axial gas jet is 0.033 , the angle between the LOX particle trace and the combustor axial is very small. Due to the large recirculation zones, premixed combustion mainly occurs in the injector wake region. As the initial LOX particle diameter increases, the LOX evaporation rate and the combustion efficiency decrease until the combustion terminates with the initial LOX particle diameter greater than $110 \mu \mathrm{m}$. The oscillation amplitude of the combustor pressure increases significantly along with the increase of the initial LOX particle diameter, and the low-frequency unstable combustion occurs when the initial LOX particle diameter exceeds $60 \mu \mathrm{m}$. The combustor pressure oscillation at about $40 \mathrm{~Hz}$ couples with the swinging process of spray and flame, while the unsteady LOX evaporation amplifies the combustor pressure oscillations at $80 \mathrm{~Hz}$ and its harmonic frequency.
\end{abstract}

\section{Introduction}

Space activities have been going on for more than half a century, and the rocket engines using toxic propellants have achieved good performance and stability in a large number of launch missions. However, toxic propellants always have the disadvantages of toxicology, high cost, and environmental pollution. With the enhancement of social awareness of environmental protection and the continuous development of manned space activities, nontoxicity propellants will inexorably become the mainstream in the future [1]. Many research results indicate that methane has advantage in various aspects, such as specific impulse, cooling capacity, and maintainability. Methane overcomes the weakness of low density of hydrogen and small specific impulse of kerosene but combines the advantages of them $[2,3]$. So the overall performance of methane is between kerosene and hydrogen. Additionally, the possibility of refining methane on Mars and Titan is conducive to the on-site refueling and reuse of aircraft in interstellar exploration [4]. Thus, $\mathrm{LOX} / \mathrm{GCH}_{4}$ bipropellant has become an important research direction of chemical propulsion.

The pintle injector has a wide range of applications, such as variable thrust adjustment and continuous rotating detonation [5]. Compared to conventional coaxial [6] and swirl [7] injectors, the pintle injector has distinguishing features of simple structure, good variable-condition adaptability, and stable combustion [8]. The abovementioned features have made a series of successful applications of the pintle injector, including the Apollo lunar descent engine (thrust ratio $10: 1$ ) [9], the main engine of the Chang'e-3 lunar probe mission (thrust ratio 5:1) $[10,11]$, and the Merlin 1D engine of the Falcon 9 rocket 
(thrust ratio $2: 1$ ) [12]. In the course of decades of development, pintle injectors have successively experienced three development directions of linear adjustment, low temperature, and nontoxicity [13]. Therefore, using pintle injectors in $\mathrm{LOX} / \mathrm{GCH}_{4}$ variable-thrust rocket engines has important research significance and broad application prospects.

The pintle rocket engine contains the pintle structure that extends into the combustor, and its combustor flow field differs greatly from traditional engines [8, 14, 15]. There are three types of main design parameters: (a) geometric parameters, including $D_{\mathrm{p}}, h, d$, and $L_{\mathrm{s}}$; (b) dimensionless parameters, including TMR (the ratio of radial jet to axial jet), BF (the ratio of the sum of orifice diameters to the pintle diameter), the skip distance-to-pintle diameter ratio, and the combustor diameter-to-pintle diameter; and (c) injection parameters, including injection speed and angle. Although the pintle injector has many design parameters and mechanisms, there are few publications about the fundamental researches of the injector. Son et al. [16-18] mainly studied the effects of TMR and Weber number on the spray cone angle and $D_{\text {SMD }}$ of gas-liquid pintle injectors. A spray simulation method and a set of pintle injector design procedures were proposed on basis of test results. Lee et al. [19] put the primary focus on spray tests of a pintle injector for improving spray uniformity in a $400 \mathrm{~N}$ class engine. The empirical correlations of spray angle and $D_{\mathrm{SMD}}$ were derived, and then, the optimum control range for the annular flow's orifice area was estimated from the perspective of atomization performance. Zhang et al. [20] analyzed the results of three cold tests and found that increasing the Weber number helps to reduce $D_{\mathrm{SMD}}$ and make its distribution more uniform. Sakaki et al. [21-24] carried out a large number of firing tests for LOX/alcohol pintle rocket engines and found that the combustion efficiency decreases as TMR increases. Besides, the coupling between the heat release rate and the combustion chamber acoustics occurs with the chamber acoustic natural frequencies when TMR is smaller than unity. Cheng et al. [7, 25-28] researched the spray characteristics of pintle injector through cold tests and theoretically derived the prediction formula of its spray cone angle. Fang and Shen [29] adopted the $D_{\text {SMD }}$ obtained in cold tests as the initial condition for two-dimensional numerical simulations and studied the effects of various structural parameters on the combustion performance of the $\mathrm{LOX} / \mathrm{GCH}_{4}$ pintle rocket engine thoroughly.

The combustion flow fields are important to understand the combustion characteristics of liquid engines. Asakawa et al. [30] observed spray distribution and evolution of flame front in a LOX/LNG rocket chamber with single coaxial injector element. Lux and Haidn [31] provided visualization of combustion flow field in a $\mathrm{LOX} / \mathrm{GCH}_{4}$ subscale thruster and studied the effect of a recessed LOX tube in shear coaxial injection on the flame roughness and stability. As for the pintle injector, Sakaki et al. [21] achieved the $\mathrm{CH} *$ chemiluminescence and backlit spray measurement of a LOX/alcohol pintle rocket engine, but the images are not clear. The related numerical works of pintle engines mostly concerned twodimensional simulations.
Generally, fundamental research about pintle injectors is little, and the published literature mainly focuses on TMR and structural parameters. In the present study, the effect of initial particle diameter on the combustion characteristics of a $\mathrm{LOX} / \mathrm{GCH}_{4}$ pintle rocket engine was studied through three-dimensional numerical simulations. The simulation results provide a reference for the design optimization and firing tests of pintle injectors.

\section{Physical Model and Numerical Methodology}

2.1. Configure. The three-dimensional structure of the LOX/GCH $\mathrm{G}_{4}$ pintle rocket engine prototype and its computational domain are shown in Figure 1. The engine comprises a gas-liquid pintle injector, a rectangular combustion chamber with an observation window, and a short contractionexpansion nozzle to choke the flow. The origin of the computational domain is the cross-section center of the combustion chamber inlet. The length, height, and width of the rectangular combustion chamber are $348 \mathrm{~mm}$ in the $x$-direction, $141 \mathrm{~mm}$ in the $y$-direction, and $45 \mathrm{~mm}$ in the $z$-direction, respectively. The heights at the nozzle throat and outlet are $8.2 \mathrm{~mm}$ and $11.9 \mathrm{~mm}$, respectively. The corresponding subsonic angle of the combustion chamber is $31^{\circ}$. Multiple monitoring points are set in the computational domain to obtain the local pressure and temperature during unsteady numerical simulations, where P01 and P02 are located in the gas manifold and P1 to P8 in the combustion chamber. The spatial coordinates of these monitoring points are shown in Table 1 . The designed mass flow rate of the engine is $598 \mathrm{~g} / \mathrm{s}(112 \mathrm{~g} / \mathrm{s}$ for LOX, $43 \mathrm{~g} / \mathrm{s}$ for $\mathrm{GCH}_{4}$, and $443 \mathrm{~g} / \mathrm{s}$ for $\mathrm{N}_{2}$, respectively), and the fuel is the premixed gas, methane and nitrogen. This helps to maintain the targeted combustor pressure $(1.8 \mathrm{MPa})$ to facilitate ignition and reduce the combustor temperature with no additional thermal protection required.

As shown in Figure 2, LOX is radially injected from 12 injection orifices at the pintle tip after passing through the pintle central flow channel. The premixed fuel gas in the gas manifold flows through the axial injection channel and impinges on the radial LOX jets with an impact angle of $90^{\circ}$. Then, the atomization and combustion occur in the combustor. The structural parameters shown in Figure 2 are listed in Table 2. For the pintle injector, the designed pressure drops for LOX and premixed fuel gas are both $1 \mathrm{MPa}$.

2.2. Numerical Method. Three-dimensional numerical simulations on the $\mathrm{LOX} / \mathrm{GCH}_{4}$ pintle rocket engine were conducted utilizing the Euler-Lagrange method in the commercial code ANSYS. The fluid phase is treated as a continuum by solving the Navier-Stokes equations, while the dispersed phase is solved by tracking a large number of particles through the calculated flow field. Flow variables in the computational domain were calculated through solving the discretized governing equations with the density-based implicit algorithm. A second-order, double-precision solver was adopted for spatial and temporal discretization with the finite volume method. The standard $k-\varepsilon$ turbulence model 


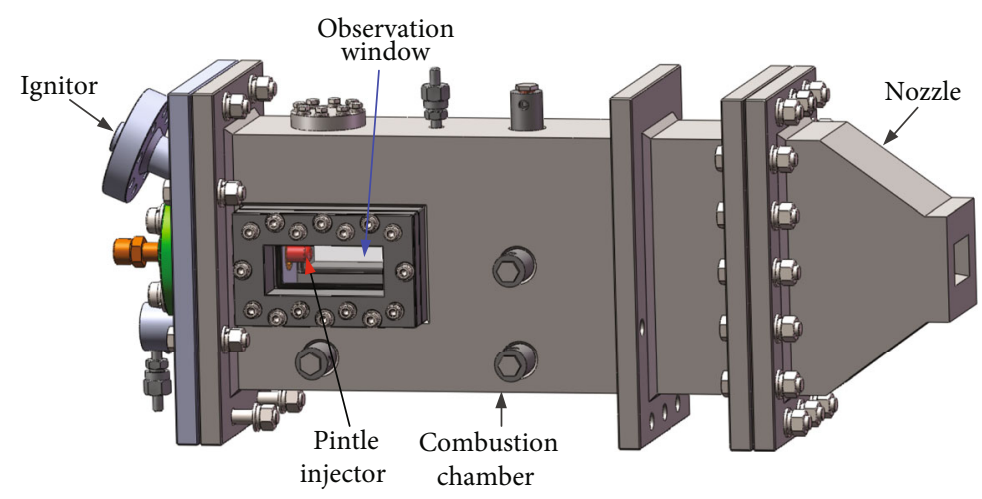

(a)

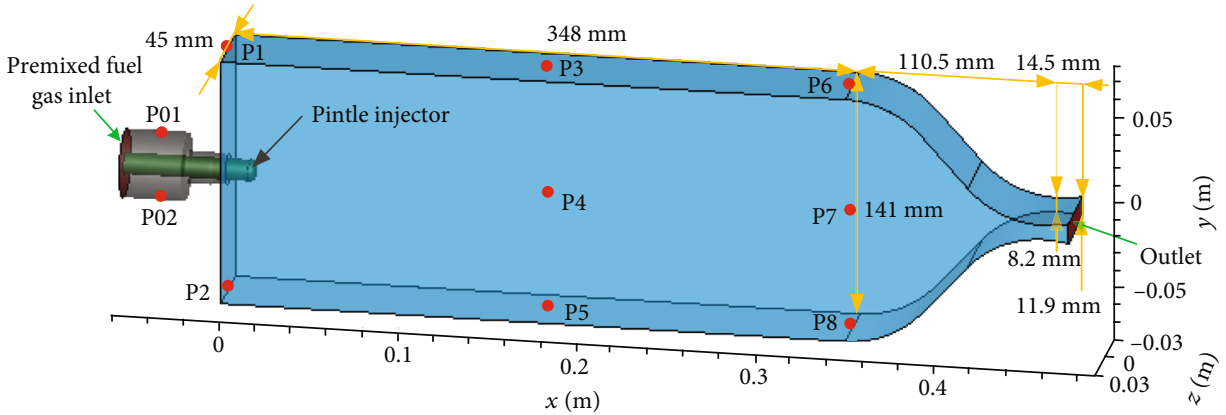

(b)

FIGURE 1: $\mathrm{LOX}_{\mathrm{GCH}}$ pintle rocket engine prototype: (a) three-dimensional structure; (b) computational domain geometry.

was applied for modeling the turbulence, and the standard wall functions are used for the near-wall treatment. The published literature show that the numerical method and its applicability for combustion flow field simulation of liquid rocket engines have been demonstrated by other researchers $[6,29]$.

In the Euler frame, the density-weighted filtered governing equations for continuous phase can be written as [32-34]

$$
\begin{gathered}
\frac{\partial \bar{\rho}}{\partial t}+\frac{\partial\left(\bar{\rho} \tilde{u}_{i}\right)}{\partial x_{i}}=\tilde{\rho}_{s}, \\
\frac{\partial\left(\bar{\rho} \tilde{u}_{i}\right)}{\partial t}+\frac{\partial\left(\bar{\rho} \tilde{u}_{i} \tilde{u}_{j}\right)}{\partial x_{j}}=\frac{\partial\left(\bar{\tau}_{i j}-\overline{\rho u_{i}^{\prime \prime} u_{j}^{\prime \prime}}\right)}{\partial x_{j}}-\frac{\partial \bar{p}}{\partial x_{j}}+\tilde{F}_{s, i} \\
\frac{\partial(\bar{\rho} \tilde{E})}{\partial t}+\frac{\partial(\bar{\rho} \tilde{E}+\bar{p}) \tilde{u}_{i}}{\partial x_{i}}=\frac{\partial\left(\overline{\tau_{i j} u_{j}}-\overline{q_{i}}-\overline{u_{i}^{\prime \prime} p-\rho u_{j}^{\prime \prime} E^{\prime \prime}}\right)}{\partial x_{i}}+\bar{S}_{h}+\tilde{Q}_{s}, \\
\frac{\partial\left(\bar{\rho} \tilde{Y}_{m}\right)}{\partial t}+\frac{\partial\left(\bar{\rho} \tilde{u}_{j} \tilde{Y}_{m}\right)}{\partial x_{i}}= \\
=\frac{\partial}{\partial x_{i}}\left(\frac{\mu_{t}}{S c_{t}} \frac{\partial \tilde{Y}_{m}}{\partial x_{i}}\right)+\frac{\partial}{\partial x_{i}}\left(\bar{\rho} \tilde{D}_{m} \frac{\partial \tilde{Y}_{m}}{\partial x_{i}}\right) \\
-\bar{\omega}_{m}+\tilde{S}_{s, m},
\end{gathered}
$$

where the over bars (-) represent the time-filtered values and the over tildes $(\sim)$ and quotes (") represent the densityweighted filtered values and their pulsation values.

In the Lagrange frame, the primary and secondary breakup processes of liquid jets are not taken into consider- ation. For simplicity, the atomization process of liquid jets is modeled as droplet particles by means of the DPM. LOX particles with a given diameter and velocity vector are injected into the computational domain from injection orifice surfaces, and no interaction between particles is yet considered. The governing equations for discrete phase can be expressed as particle trajectory equations, and unsteady Lagrange particle tracking method was used to describe the motion and evaporation of each particle. The discrete random walk model could predict the turbulent dispersion of particles by integrating the effect of instantaneous turbulent velocity fluctuations on the particle trajectories. The spherical drag law was adopted without considering the nonsphericity of the droplet shape. The interaction of the droplet with combustor walls utilized the reflect-type boundary condition with all normal and tangential momentum retained. During the calculation process, required information of the surrounding gas is provided by the governing equations for continuous phase, while the gas source terms are calculated and delivered to the latter. For the details of DPM, the reader should consult Ref. [35].

In the present simulation, the EDC was applied for turbulent combustion simulation, and the reaction rate of every reaction is calculated individually by formulating smallscale eddies. The eddy scale is governed by the turbulent kinetic energy and the turbulent dissipation rate in turbulence flow. Giorgi et al. [36] compared multiple turbulent combustion models for the coaxial rocket engine and revealed that the EDC was numerically cheaper to predict the combustor temperature and flame length. Besides, the 
TABLE 1: The spatial coordinates of all monitoring points.

\begin{tabular}{lccccccccccc}
\hline & P01 & P02 & P1 & P2 & P3 & P4 & P5 & P6 & P7 \\
\hline$x(\mathrm{~m})$ & -0.028 & -0.028 & 0 & 0 & 0.174 & 0.174 & 0.174 & 0.348 & 0.348 & 0.348 \\
$y(\mathrm{~m})$ & 0.018 & -0.018 & 0.07 & -0.07 & 0.07 & 0 & -0.07 & 0.07 & 0 & -0.07 \\
$z(\mathrm{~m})$ & 0 & 0 & 0 & 0 & 0 & 0 & 0 & 0 & 0 & 0 \\
\hline
\end{tabular}

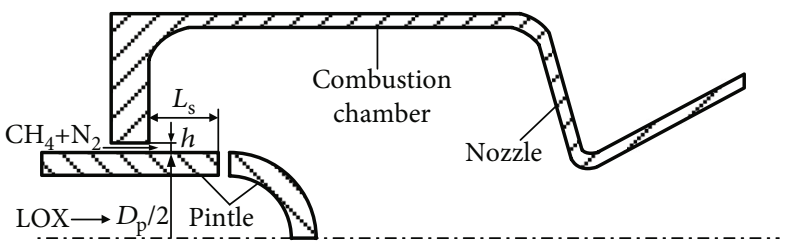

(a) Pintle engine

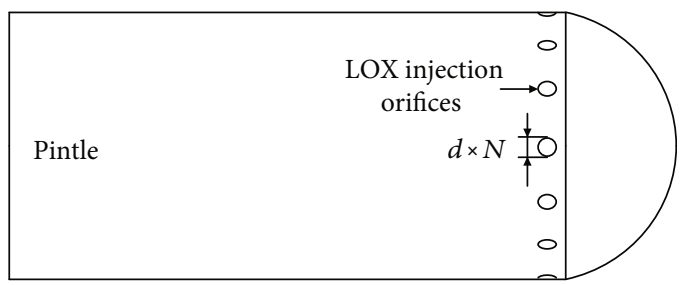

(b) Pintle tip

Figure 2: Schematic of $\mathrm{LOX} / \mathrm{GCH}_{4}$ rocket engine with pintle injector.

TABLE 2: Main structural parameters of the pintle injector.

\begin{tabular}{lcccc}
\hline$L_{\mathrm{s}}(\mathrm{mm})$ & $D_{\mathrm{p}}(\mathrm{mm})$ & $h(\mathrm{~mm})$ & $d(\mathrm{~mm})$ & $N$ \\
\hline 12 & 12 & 2.23 & 0.56 & 12 \\
\hline
\end{tabular}

JL mechanism is used to model real chemical reactions, as listed in Table 3. Andersen et al. [37] combined the JL with the EDC and provided an accurate temperature field and $\mathrm{CO}$ distribution under the oxygen-methane condition.

2.3. Validation of the Euler-Lagrange Method. Yuan [6] adopted the Euler-Lagrange method to simulate the combustion flow field of an air heater. The LOX spray length and cone angle obtained with numerical simulations are identical to the high-speed photography results. In this section, the optical measurement data from Ref. [38] was employed to further examine the validity of the Euler-Lagrange method in the study of spray, evaporation, and mixing. The corresponding computational domain is the rectangular duct, as shown in Figure 3. The red zone represents the inlet of heated air with a velocity of $120 \mathrm{~m} / \mathrm{s}$ and a temperature of $750 \mathrm{~K}$. The kerosene injection surface is located in the center of the red zone, from which liquid-kerosene jet $(1 \mathrm{~g} / \mathrm{s})$ is injected into the rectangular duct at $453 \mathrm{~K}$. The injected kerosene has a streamwise velocity component of $10 \mathrm{~m} / \mathrm{s}$, while its transverse velocity component is neglected. The outlet pressure and the operation pressure are set to $0.9 \mathrm{MPa}$ and 0 , respectively. The dimensions of the rectangular duct are $25 \mathrm{~mm} \times 40 \mathrm{~mm} \times$ $150 \mathrm{~mm}$, and those of the kerosene injection surface are 5 $\mathrm{mm} \times 1 \mathrm{~mm}$. The pressure within the rectangular duct is constant at about $0.9 \mathrm{MPa}$. According to the precise spray boundary conditions provided by Ref. [38], the RosinRammler distribution with the $D_{\mathrm{SMD}}$ of $14.6 \mu \mathrm{m}$ is applied to the initial kerosene particle diameter.

The spray trajectories of kerosene particles in the rectangular duct are shown in Figure 4, and these small spheres are colored by particle mass. Kerosene particles gradually evaporate as they flow downstream, and the evaporation products diffuse into heated air. This results in a decrease in the streamwise velocity component of the surrounding gas around the center of the rectangular duct, as shown in the velocity distribution of Figure 4 . Because the transverse velocity component of kerosene particles at the injection surface is neglected in the numerical simulation, the dispersion ranges of kerosene particles in the $x$ - and $y$-direction are slightly narrower than the experimental results shown in Ref. [38].

Figure 5 presents the quantitative comparisons of the numerical and experimental results [38], which include the $D_{\text {SMD }}, D_{0.1}$, and $D_{0.9}$, as well as a cross-sectional averaged degree of evaporation. The degree of evaporation is defined as the ratio of the evaporated to the initial kerosene mass flow rate at one certain plane. Generally, the numerical results agree well with Ref. [38], while the difference is mainly due to the uncertainties of boundary conditions and kerosene physical properties. Thus, the Euler-Lagrange method can be applied to simulate the evaporation characteristics of liquid jets.

2.4. Boundary Conditions and Computational Mesh. For the computational domain in Figure 1(b), the characteristic inflow condition with constant temperature $(300 \mathrm{~K})$, mass flow rate, and species mass fraction was utilized at the inlet of premixed fuel gas, methane and nitrogen. The LOX jets were assumed as fully atomized spray composed by spherical droplet particles at $80 \mathrm{~K}$. The injection velocity of $33.48 \mathrm{~m} / \mathrm{s}$ is perpendicular to the outlet surfaces of 12 LOX injection orifices. The initial particle diameter uses uniform distribution with $D_{\mathrm{SMD}}$. The supersonic outflow condition was employed at the nozzle outlet, and the outlet pressure was extrapolated from the solution. The adiabatic, nonslip wall condition was applied for the numerical studies, and the walls will reflect the LOX particles after collision.

Figure 6 displays the continuous joint mesh of the $\mathrm{LOX} / \mathrm{GCH}_{4}$ pintle rocket engine. Unstructured mesh with tetrahedral cells was used for meshing the combustor and nozzle, while structured mesh with cuboidal cells for the 
TABLE 3: Jones-Lindstedt global multistep methane combustion mechanism [37].

\begin{tabular}{lccccc}
\hline No. & Reactions & Preexponential factor & Temperature exponent & Activation energy (cal/mol) & Reaction orders \\
\hline JL1 & $\mathrm{CH}_{4}+0.5 \mathrm{O}_{2}=>\mathrm{CO}+2 \mathrm{H}_{2}$ & $7.82 \times 10^{13}$ & 0 & $30.0 \times 10^{3}$ & {$\left[\mathrm{CH}_{4}\right]^{0.5}\left[\mathrm{O}_{2}\right]^{1.25}$} \\
JL2 & $\mathrm{CH}_{4}+\mathrm{H}_{2} \mathrm{O}=>\mathrm{CO}+3 \mathrm{H}_{2}$ & $0.30 \times 10^{12}$ & 0 & $30.0 \times 10^{3}$ & {$\left[\mathrm{CH}_{4}\right]\left[\mathrm{H}_{2} \mathrm{O}\right]$} \\
JL3 & $\mathrm{H}_{2}+0.5 \mathrm{O}_{2}<=>\mathrm{H}_{2} \mathrm{O}$ & $1.21 \times 10^{18}$ & -1 & $40.0 \times 10^{3}$ & {$\left[\mathrm{H}_{2}\right]^{0.25}\left[\mathrm{O}_{2}\right]^{1.5}$} \\
JL4 & $\mathrm{H}_{2} \mathrm{O}+\mathrm{CO}<=>\mathrm{H}_{2}+0.5 \mathrm{O}_{2}$ & $2.75 \times 10^{12}$ & 0 & $20.0 \times 10^{3}$ & {$\left[\mathrm{H}_{2} \mathrm{O}\right][\mathrm{CO}]$} \\
\hline
\end{tabular}

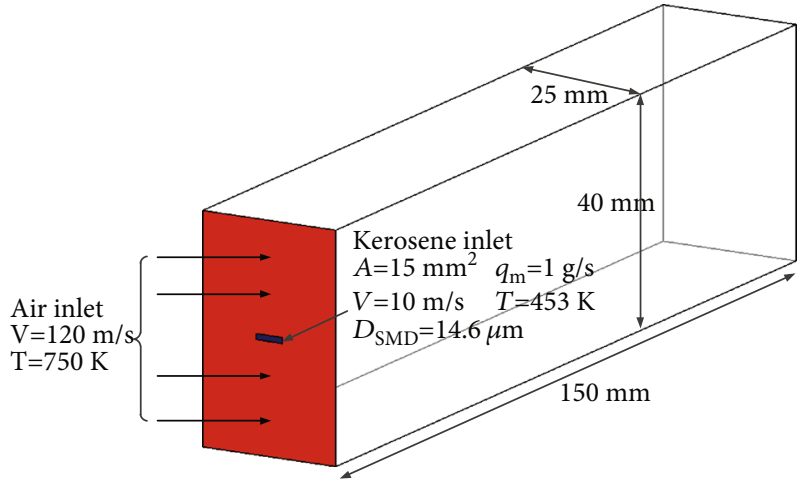

FIGURE 3: Schematic of the computational domain and boundary conditions for validation of the Euler-Lagrange method.

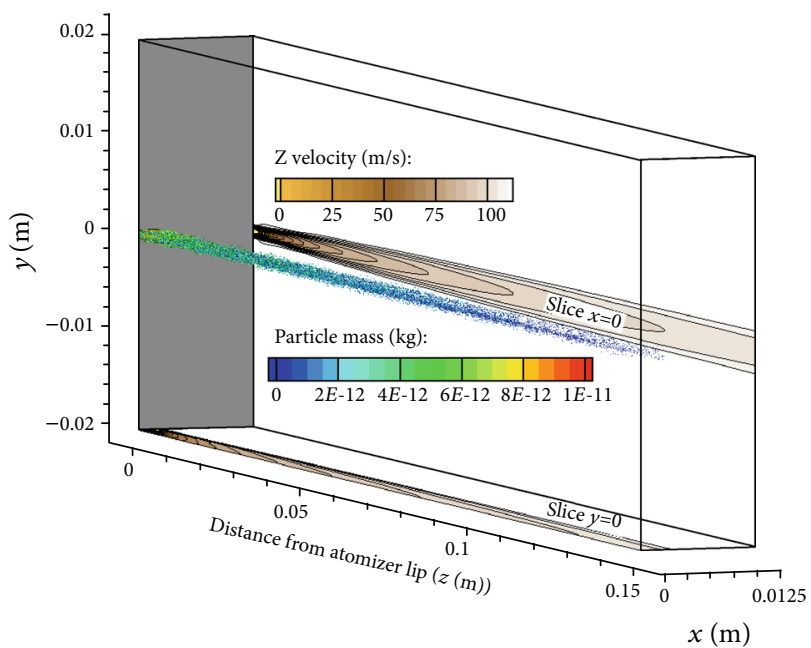

FIgURE 4: Spray trajectories and distribution of streamwise velocity component in the symmetry planes $(x=0$ and $y=0)$ of the duct.

gas manifold and axial injection channel. In order to better resolve the flames and shear layers, the corresponding grids were clustered in the surrounding region of the injector wake and combustor walls.

\section{Results and Discussion}

To study the combustion characteristics of the $\mathrm{LOX} / \mathrm{GCH}_{4}$ pintle rocket engine, cases with different initial particle diameters were considered, while the computational domain (as shown in Figure 1) and other numerical simulation setups remain in the same. The initial particle diameter of $10 \mu \mathrm{m}$ was chosen as the basic case.

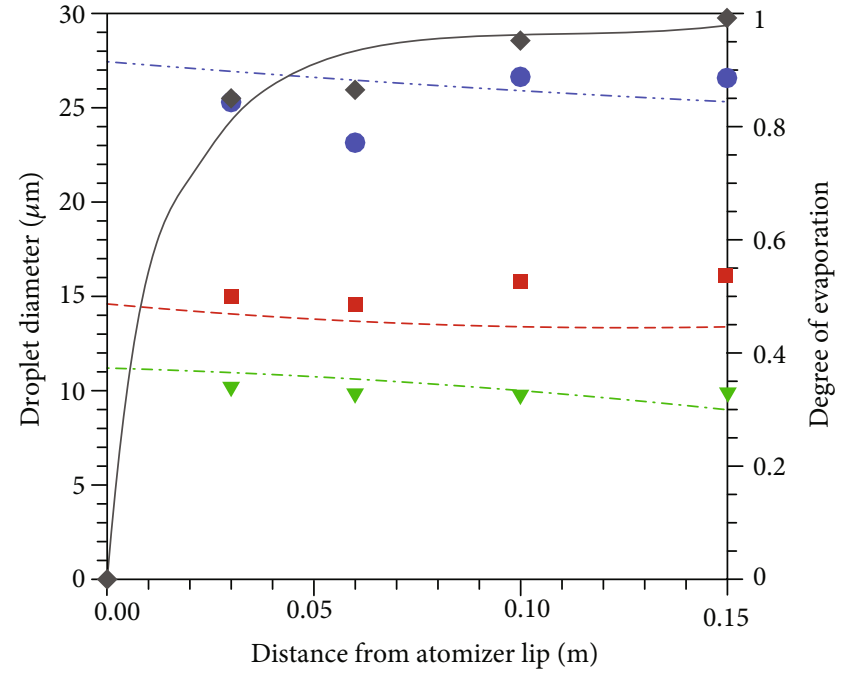

$$
\begin{aligned}
& \text { Exp. Sim. } \\
& \text { - } \quad--\mathrm{D}_{\mathrm{SMD}} \\
& \checkmark \quad \cdot-\cdot \mathrm{D}_{0.1} \\
& \text { - } \quad \cdots-\cdots \mathrm{D}_{0.9} \\
& \text { - — Degree of evaporation }
\end{aligned}
$$

FIgURE 5: Comparison of numerical and experimental results [38] on representative particle sizes and cross-sectional averaged degree of evaporation.

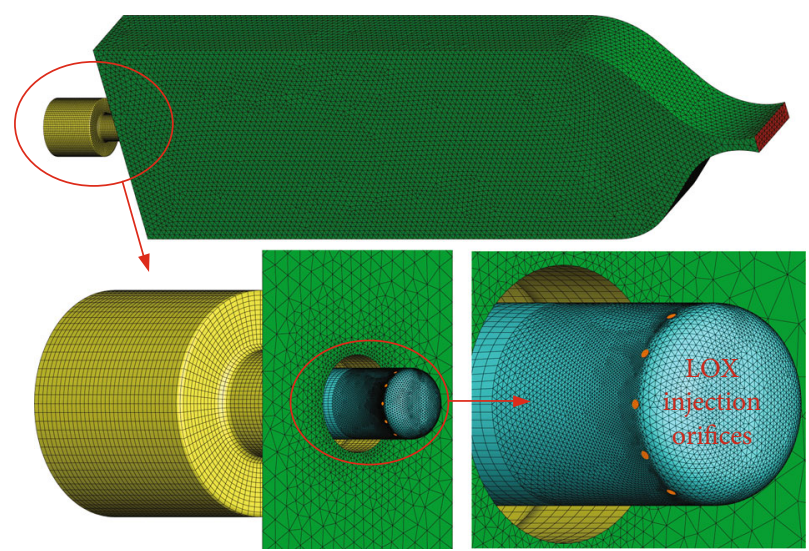

FIgURE 6: Computational mesh of LOX/GCH4 pintle rocket engine.

3.1. Basic Case. In this section, four sets of mesh were used for the steady simulation of the basic case. Mesh A, B, C, and D have a total of $503665,740924,988070$, and 1260312 cells, respectively. As shown in Figure 7, the recirculation zones and spray trajectories obtained with 4 sets of mesh are similar 


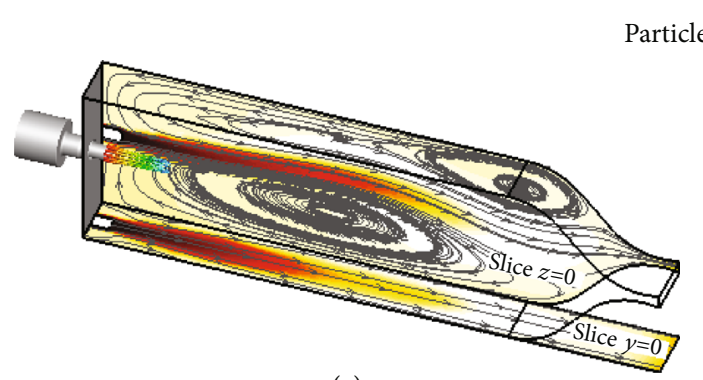

(a)

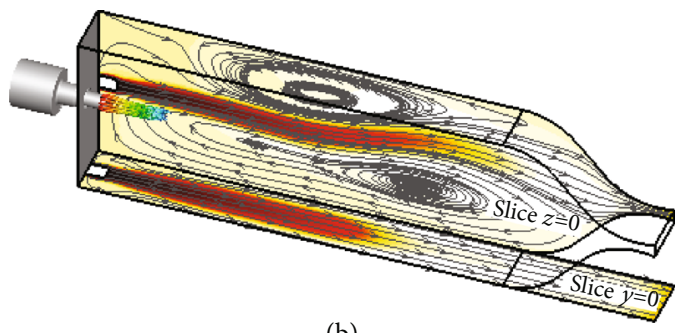

(b)

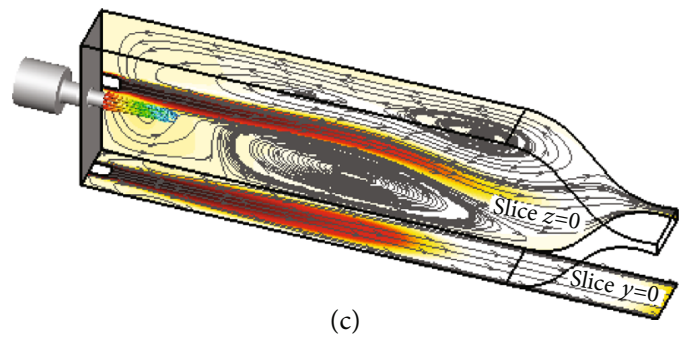

(c)

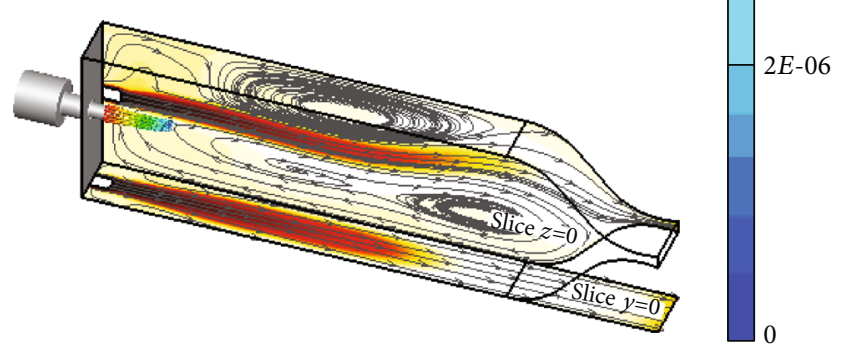

(d)

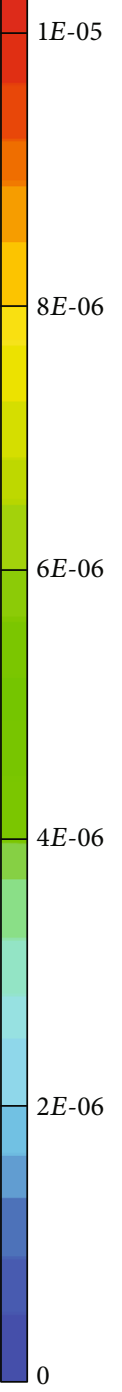

E-06

Temperature (K):

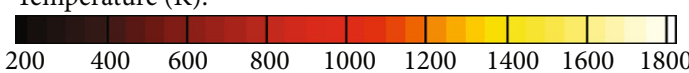

FIGURE 7: LOX particle traces and distribution of temperature fields and streamline in $y=0$ and $z=0$ planes for different mesh resolutions: (a) mesh A; (b) mesh B; (c) mesh C; (d) mesh D.

to each other. However, it can be seen from Figure 8 that the difference of local $x$-velocity distribution for mesh $\mathrm{B}, \mathrm{C}$, and $\mathrm{D}$ is small, but not for mesh A. This illustrates that mesh B, $\mathrm{C}$, and D can properly capture the expansion feature of the premixed fuel gas in the downstream of the pintle tip.

Besides, Figure 8 shows that the cross-sectional area of gas-flow channel is reduced before the premixed fuel gas enters the combustor, while the axial velocity of subsonic gas flow increases gradually. Under the influence of the large recirculation zones between combustor walls and combustor axis in Figure 7, the premixed fuel gas continues to flow along the pintle wall with the same axial velocity after leaving the axial injection channel. The hemispherical shape of the pintle tip results into a local high-pressure zone with small axial velocity near the pintle tip, which is significantly different from that of the previous two-dimensional simulations [29, 39]. The large recirculation zones and local high-pressure zone cause throttling area reduction when the premixed fuel gas approaches the pintle tip. Correspondingly, the axial velocity of the premixed fuel gas increases to the sound speed first and then decreases. As the TMR is small (0.033), LOX particles are convected downstream by the premixed fuel gas after being injected radially from the injection orifices. The angle between the LOX particle trace and the combustor axial is very small, and the particles are dispersed in a conical shape. The LOX particles move streamwise and are completely evaporated at $x=65 \mathrm{~mm}$.

The temperature fields for different grid resolutions in Figure 7 are also similar. The high-temperature reaction products are transferred to the head of the combustor due 


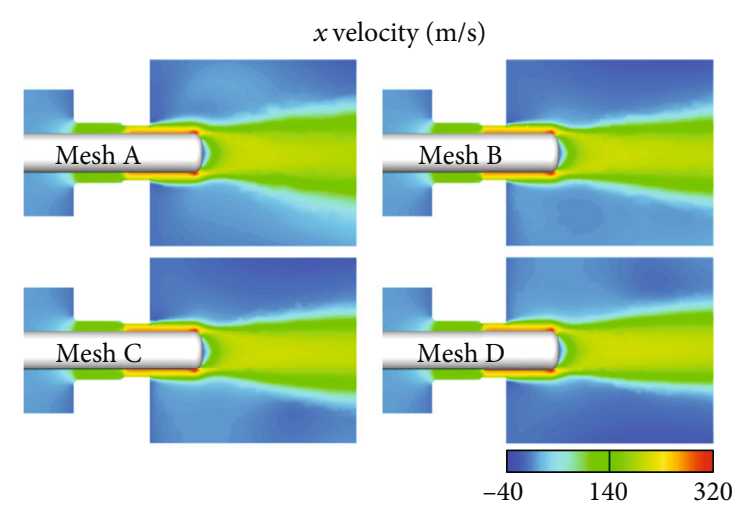

FIGURE 8: Close-up plots of $x$-velocity distribution in the vicinity of the pintle tip for different mesh resolutions.

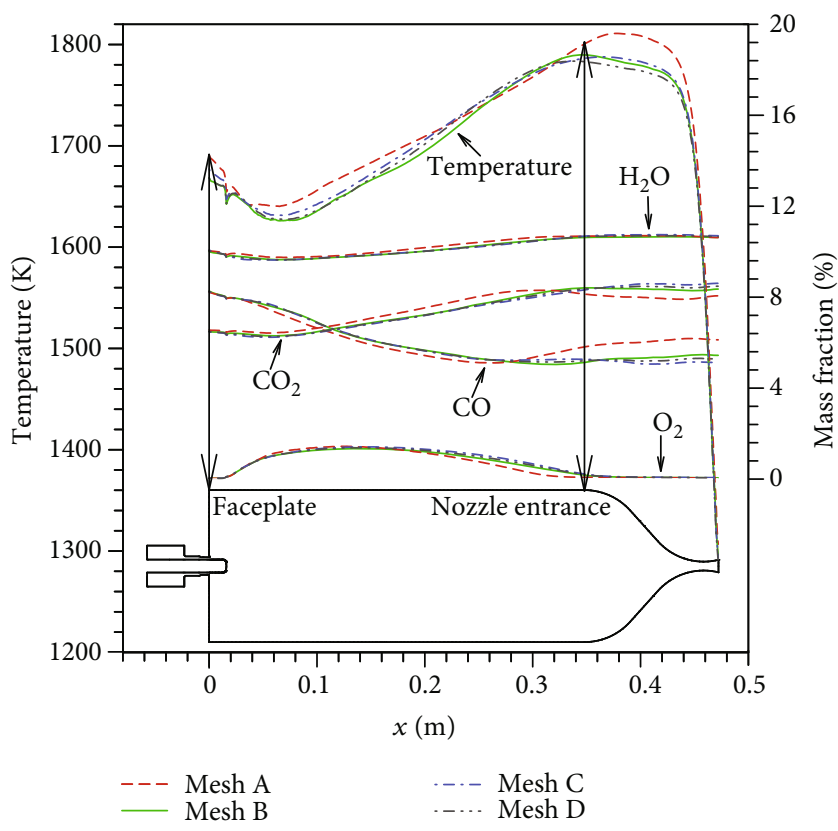

FIgURE 9: Cross-sectional averaged combustor temperature and species mass fraction $\left(\mathrm{O}_{2}, \mathrm{CO}, \mathrm{CO}_{2}\right.$, and $\left.\mathrm{H}_{2} \mathrm{O}\right)$ versus the combustor axis for different mesh resolutions.

TABle 4: Comparison of simulation results for different mesh resolutions and designed values.

\begin{tabular}{lccccc}
\hline & Mesh A & Mesh B & Mesh C & Mesh D & Designed value \\
\hline$p_{c}(\mathrm{MPa})$ & 1.8226 & 1.7977 & 1.8040 & 1.8015 & 1.8 \\
$T_{\mathrm{c}}(\mathrm{K})$ & 1695.57 & 1671.62 & 1684.74 & 1679.30 & 1679 \\
$c^{*}(\mathrm{~m} / \mathrm{s})$ & 1125.99 & 1110.58 & 1114.53 & 1112.96 & 1126.36 \\
$\eta_{c}{ }^{*}(\%)$ & 99.97 & 98.60 & 98.95 & 98.81 & - \\
\hline
\end{tabular}

to the large recirculation zones, which contributes to the uniform temperature distribution in the combustor and the lowtemperature zone in the vicinity of pintle tip and combustor axis. Premixed combustion occurs at the border of the highand low-temperature zones. In addition, the asymmetry of the combustion flow field with respect to the $y=0$ plane is

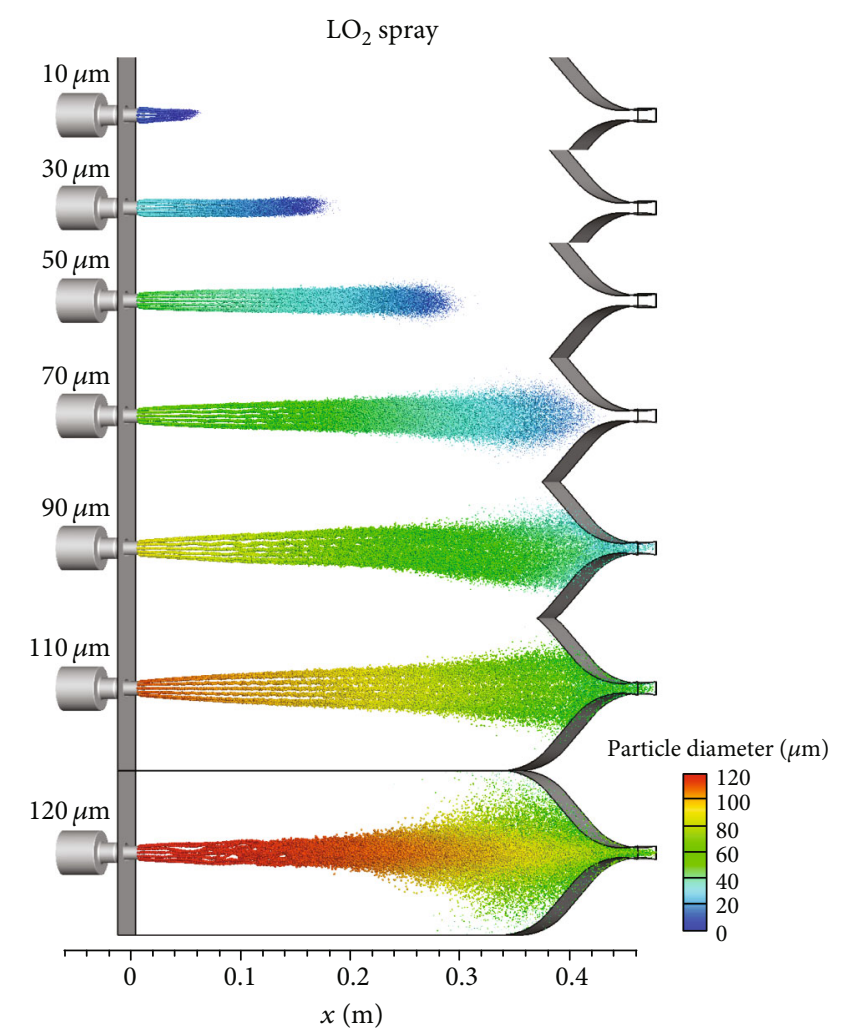

Figure 10: LOX spray trajectories of for different initial particle diameters.

mainly caused by the Reynolds number and the expansion ratio of the axial injection channel [40,41]. Under the numerical simulation setups, the Reynolds number of the premixed fuel gas in the axial injection channel is $7.93 \times$ $10^{6}$, and the expansion ratio (the ratio of the height of the combustion chamber to the outer diameter of the axial injection channel) is 8.56. As the Reynolds number and expansion ratio are both large, the asymmetry of the combustion flow field appears with a certain randomness, but the main structure of the combustion flow field is similar.

The quantitative comparison results for mesh independence analysis are shown in Figure 9. It can be seen that, compared with the results of mesh $\mathrm{D}$, the relative deviations of mesh $\mathrm{B}$ and $\mathrm{C}$ are negligible, while those of mesh $\mathrm{A}$ is large.

In this study, the combustion efficiency is estimated with $\eta_{c}{ }^{*}$, which is evaluated with Equations (2) and (3). $c_{\mathrm{th}}{ }^{*}$ is calculated with NASA Chemical Equilibrium with Applications (NASA CEA) [42]. $q_{\mathrm{m}}$ is the designed mass flow rate $(0.598 \mathrm{~kg} / \mathrm{s})$ of the engine, and the $A_{\mathrm{t}}$ is the geometric area $(45 \mathrm{~mm} * 8.22 \mathrm{~mm})$ of the rectangular-shaped throat.

$$
\begin{aligned}
\eta_{c *} & =c^{*} / c_{t h}^{*}, \\
c^{*} & =p_{c} A_{t} / q_{m} .
\end{aligned}
$$

As listed in Table 4, the simulation results for different mesh resolutions were compared with the designed values obtained with NASA CEA. Compared with the designed values, all the relative deviations of $T_{c}, p_{c}$, and $c^{*}$ for different 


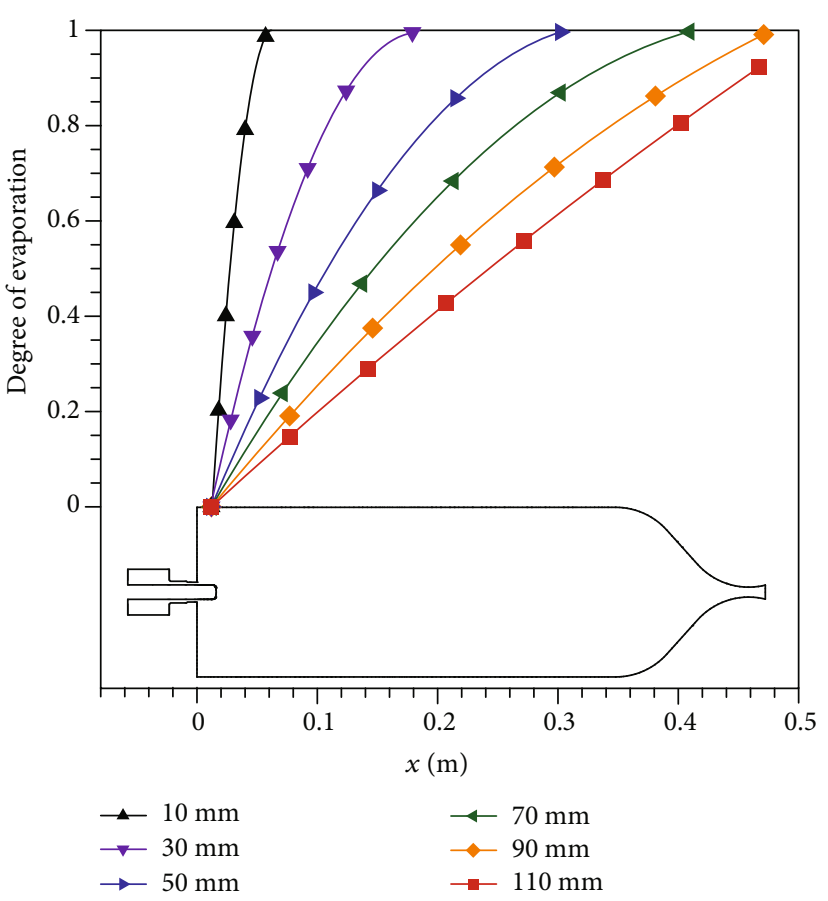

(a)

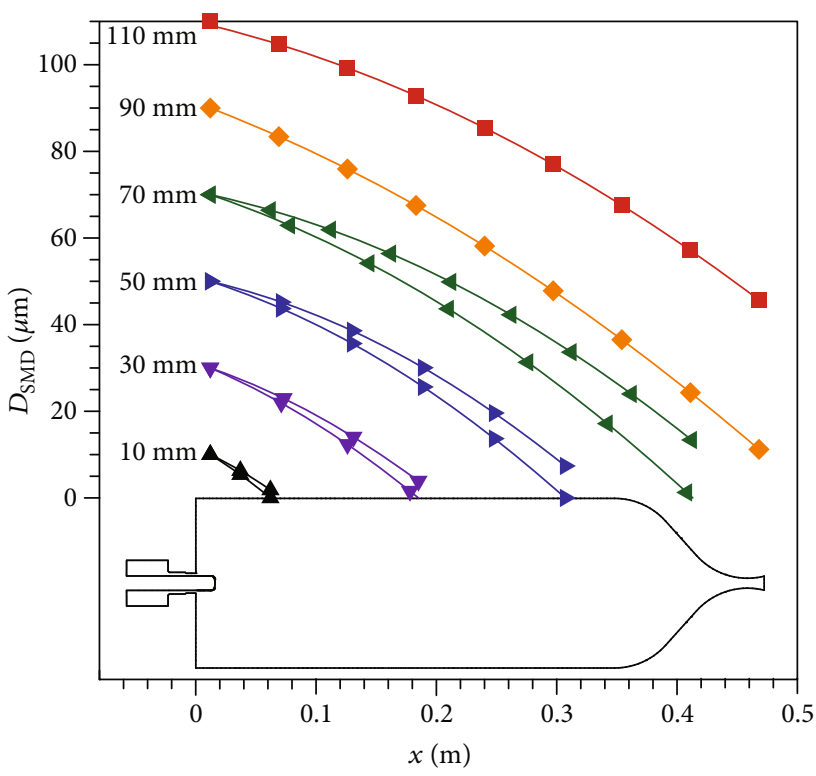

(b)

Figure 11: Cross-sectional averaged degree of evaporation (a) and $D_{\mathrm{SMD}}$ (b) versus the combustor axis for different initial particle diameters.

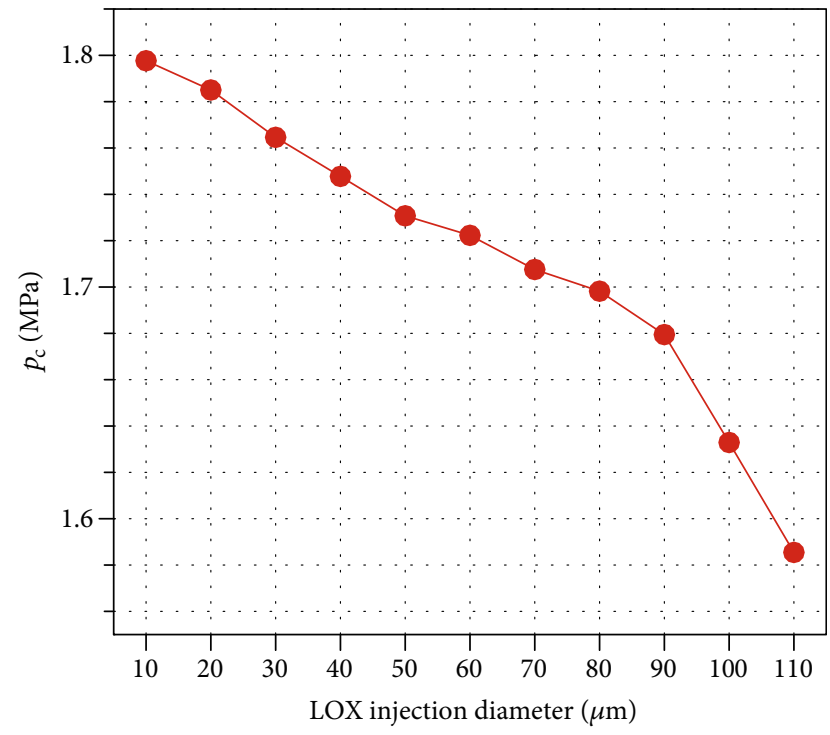

FIgURe 12: Combustor pressure for different initial LOX particle diameters.

grid resolutions are less than $2 \%$. It should be noted that $p_{c}$ and $T_{c}$ refer to the area-weighted average value of the entire combustor $(0 \leq x \leq 348 \mathrm{~mm})$. And all the combustion efficiencies are higher than $98 \%$, which demonstrates the validity of the engine configuration and numerical simulation setup. However, the $\eta_{c}{ }^{*}$ for mesh $\mathrm{A}$ is close to $100 \%$, and the streamwise length of the lowtemperature region is shorter than that of the others (as seen in Figure 7), indicating that the combustion reaction for mesh $\mathrm{A}$ is more violent. To the viewpoint of computational time, mesh B is suitable and sufficient for the subsequent calculation simulations.

3.2. Evaporation Characteristics. The evaporation characteristics of the pintle injector are mainly evaluated by the spray trajectories and particle size distribution. Keeping other setups unchanged, 12 steady simulation cases were conducted with different initial LOX particle diameters $(10 \sim 120 \mu \mathrm{m}$, changed per $10 \mu \mathrm{m})$. Spray trajectories for different initial LOX particle diameters are displayed in Figure 10, and the sphere color represents the particle diameter. It can be seen that the dispersion characteristics of LOX particles are sensitive to the initial particle diameter. As the initial particle size increases, the streamwise length of spray trajectories gradually increases until some particles leave the engine without evaporating completely. The transverse diffusion degree of LOX particles along the flow direction also alters significantly for different initial particle diameters. The spray trajectories contract to the combustor axis with the initial LOX particle diameter of $10 \mu \mathrm{m}$. The larger the initial particle diameter is, the more obvious the radial expansion trend of the spray trajectories becomes. When LOX particles enter the combustor with the initial particle diameter of $120 \mu \mathrm{m}$, more LOX particles have not completely evaporated in the combustor, and the combustion terminates as there is not enough oxygen to participate in chemical reaction.

As illustrated in Figure 11, under the same mass flow rate condition, the evaporation rate of the LOX particles with a smaller initial particle diameter is faster than those with larger initial particle diameter, and so does the decrease rate 


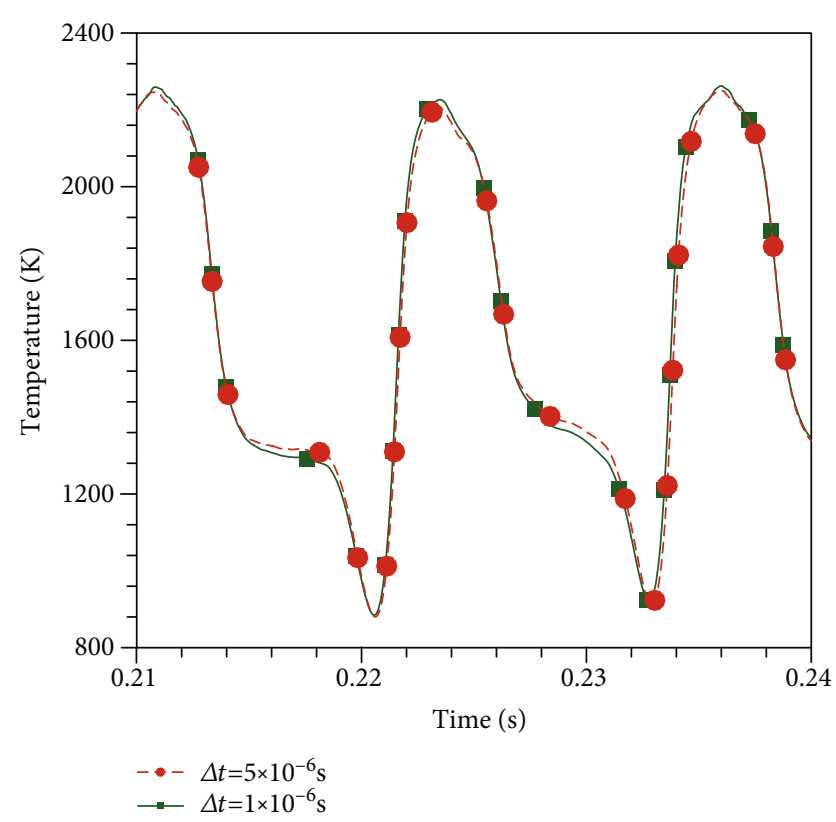

Figure 13: Time histories of the temperature oscillations at $\mathrm{P} 4$ with different time steps for the initial LOX particle diameter of $60 \mu \mathrm{m}$.

of $D_{\mathrm{SMD}}$. This is because the total surface area of the droplets is inversely proportional to the initial particle diameter, and the heat exchange from LOX particle surfaces with the surrounding gas is stronger with smaller initial particle diameter. The temperature of LOX particles gradually increases as the evaporation proceeds. And the decrease of LOX particle diameter leads to a reduced heat transfer area. Thus, the evaporation rate of LOX particles decreases along with the combustor axis.

The initial particle diameter is an important factor that affects the performance of the $\mathrm{LOX} / \mathrm{CH}_{4}$ pintle engine. Figure 12 shows the change curve of the combustor pressure with respect to the initial LOX particle diameter. The increase of the initial LOX particle diameter leads to the decrease of the evaporation rate, and less time is left for oxygen to react with methane. The inadequate chemical reactions will lead to reduced combustion efficiency, which is proportional to the combustor pressure. When the initial LOX particle diameter is larger than $90 \mu \mathrm{m}$, the incomplete evaporation of some particles causes the further decline of the amount of oxygen required for the combustion reaction, and the combustion efficiency is accelerated to decrease until the combustion terminates. The initial LOX particle diameter of $110 \mu \mathrm{m}$ is the limit for maintaining combustion under the fuel-rich condition (the residual oxygen coefficient is 0.65 ). So, it is necessary to improve the atomizing performance of the pintle injector.

3.3. Combustion Stability. In this section, unsteady simulations with different initial LOX particle diameters, $10 \mu \mathrm{m}$, $60 \mu \mathrm{m}$, and $110 \mu \mathrm{m}$, were conducted to further investigate the effects of the latter on the combustion stability of the $\mathrm{LOX} / \mathrm{CH}_{4}$ pintle engine. The starting moments of unsteady simulations were set as $0 \mathrm{~s}$ of combustion process. Combus- tion stability was mainly evaluated in terms of the $P^{\prime}$ in the combustor during the steady stage, and the threshold of $3 \%$ is used to classify the stable and unstable combustion [43]. The locations of the monitoring points associated with the oscillation traces mentioned below are listed in Figure 1 and Table 1.

The time step $\Delta t$ has a great effect on the simulation results and should meet the following condition generally:

$$
\frac{u \cdot \Delta t}{\Delta x}<1
$$

where $\Delta t$ is the time step, $u$ is the characteristic flow velocity, and $\Delta x$ is the local grid size.

The injection velocity of the premixed fuel gas is $236.75 \mathrm{~m} / \mathrm{s}$, and the minimum grid size near the pintle tip for mesh $\mathrm{B}$ is $0.47 \mathrm{~mm}$. Thus, $\Delta t$ should be smaller than $1.99 \times 10^{-6} \mathrm{~s}$. In order to reduce the numerical costs of unsteady simulation, unsteady simulations with two different time steps, $1 \times 10^{-6} \mathrm{~s}$ and $5 \times 10^{-6} \mathrm{~s}$, were used to demonstrate the time step convergence. It can be seen from Figure 13 that, under the initial LOX particle diameter of $60 \mu \mathrm{m}$, the time histories of the temperature oscillations at the monitoring point, $\mathrm{P} 4$, for the two different time steps are basically the same. So, $5 \times 10^{-6} \mathrm{~s}$ was selected as the time step for the following unsteady simulations.

For different initial LOX particle diameters, Figure 14 shows the time histories of the pressure oscillations at P3 and $\mathrm{P} 01$ and the corresponding $P^{\prime}$ during the steady stage. As illustrated in Figure 14, the combustion stability is closely related to the initial LOX particle diameter. As the initial LOX particle diameter increases, the time-averaged value of the combustor pressure decreases, but the corresponding $P^{\prime}$ increases. The $P^{\prime}$ of the combustor pressure is always lower than $5 \%$ due to the intrinsic combustion stability of the pintle injector. The unstable combustion (the $P^{\prime}$ of the combustor pressure $>3 \%$ ) only occurs when the initial LOX particle diameter is greater than $60 \mu \mathrm{m}$. The pressure oscillation in the gas manifold is almost synchronous to that in the combustor, and the former is only slightly lagging behind the latter. However, the $P^{\prime}$ of the injection pressure in the gas manifold is smaller than $0.5 \%$ and has a nonlinear relationship with the initial LOX particle diameter. Thus, no coupling occurs between the combustor pressure and gas injection pressure.

As displayed in Figure 15, the spectrogram plots of the combustor pressure fluctuations for different LOX particle diameters are similar, and strong peaks are observed in the vicinity of several main frequencies, $40 \mathrm{~Hz}, 80 \mathrm{~Hz}$, and $160 \mathrm{~Hz}$. As the initial LOX particle diameter increases, the main frequencies decrease slightly, while the corresponding amplitudes increase significantly.

From the evolution of the combustion flow field for different initial LOX particle diameters in one period of pressure oscillation in Figure 16, it can be seen that the spray and flame swing in the $y$-direction for different initial LOX particle diameters. The evaporation rate decreases along with the increase of the LOX particle diameter, and the reaction 


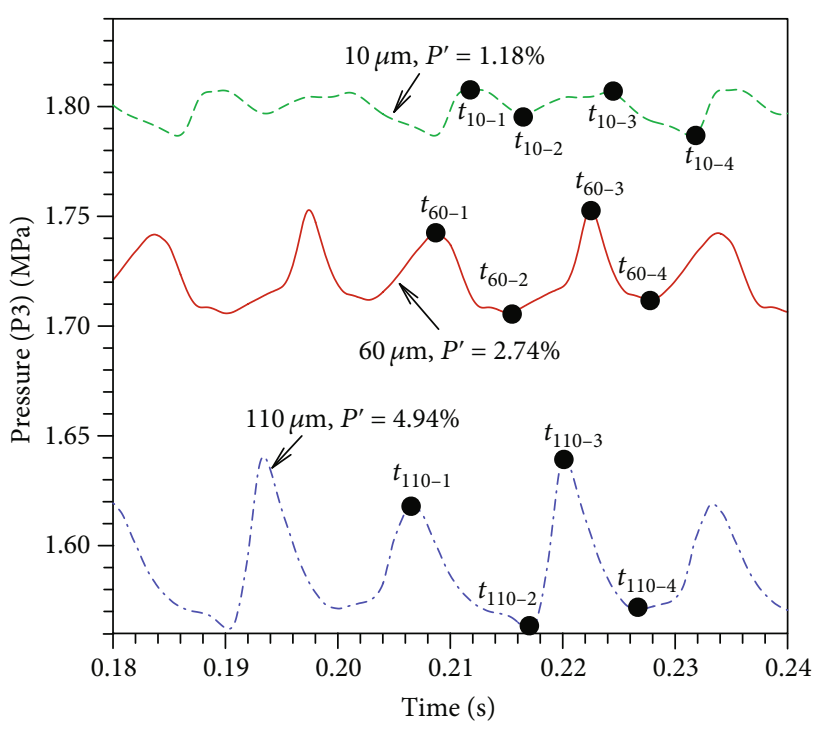

(a)

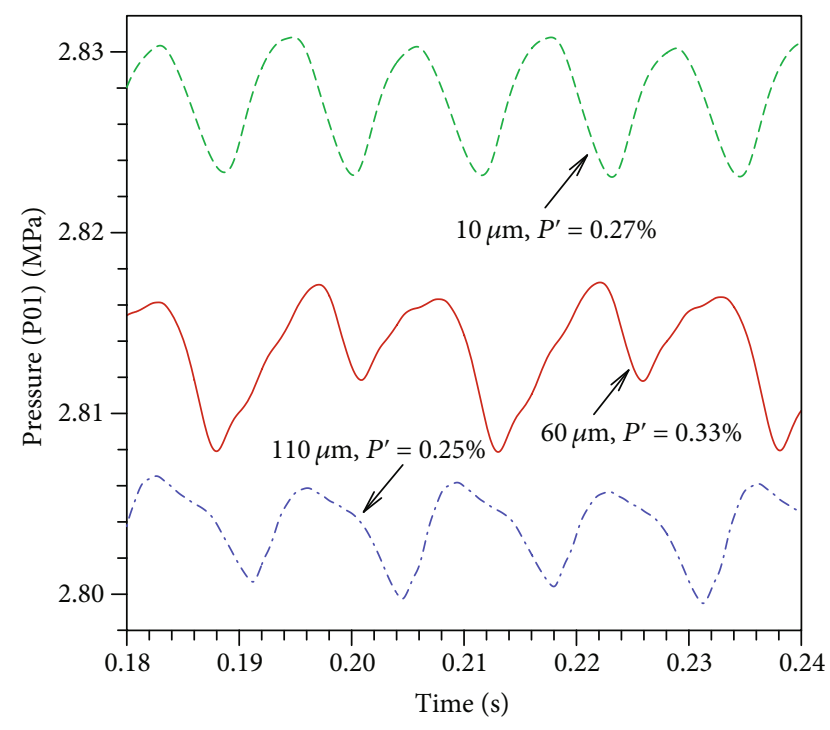

(b)

FIGURE 14: Time histories of the pressure oscillations for different initial LOX particle diameters: (a) combustor (P3); (b) gas manifold (P01).

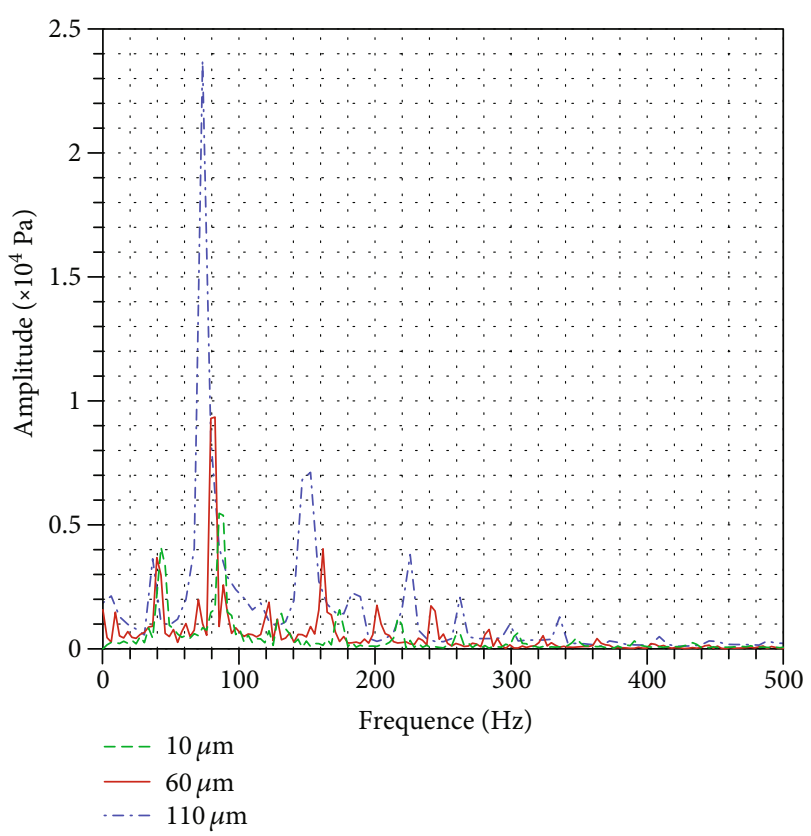

FIGURE 15: Spectrogram plots of the pressure trace at P3 for different initial LOX particle diameters shown in Figure 14(a).

region spreads downstream of the combustor with LOX spray. This exacerbates the degree of temperature field inhomogeneity in the combustor and the swinging scope of the spray and flame.

Figure 17 shows the time histories of the LOX evaporation rate oscillations and their spectrogram plots during the steady stage for different initial particle diameters. The streamwise length of the spray trajectory is short when the initial LOX particle diameter is $10 \mu \mathrm{m}$, and the evaporation rate does not show regular oscillations. When the initial LOX particle diameter is $60 \mu \mathrm{m}$, the streamwise length of spray trajectory extends significantly, and the evaporation rate has peaked at $80 \mathrm{~Hz}$ and its harmonic frequency (for a detailed explanation, see Ref. [44]). The LOX evaporation rate oscillates almost in phase with the combustor pressure. According to the Rayleigh criterion, the unsteady evaporation process of LOX droplets maintains combustor pressure oscillation ( $80 \mathrm{~Hz}$ and its harmonic frequency).

The oscillation amplitude of the evaporation rate increases dramatically with the initial LOX particle diameter increasing to $110 \mu \mathrm{m}$, while the oscillation frequency decreases slightly compared to the initial LOX particle diameter of $60 \mu \mathrm{m}$. The phase difference between the oscillation waveforms of the LOX evaporation rate and the combustor pressure significantly increases, and the occurrence moments of the local high-temperature region (Figure 16) and the combustor pressure peak (Figure 14(a)) indicate that the heat release rate is almost antiphase to the pressure oscillation. This means that the initial LOX particle diameter of $110 \mu \mathrm{m}$ is the upper limit for maintaining low-frequency unstable combustion under such condition, as mentioned in Section 3.2, and a further increase will make the combustion terminate. In addition, the time-averaged evaporation rate becomes smaller as some particles leave the engine without complete evaporation.

Tamura et al. [45] conducted experimental research of the low-frequency combustion instability of the LOX/hydrogen rocket engine and found that there is coupling between the streamwise length of LOX spray trajectories and the combustor pressure. But they did not give the relevant flame behaviors. The present numerical study found that, for the

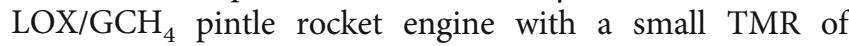
0.033 , the low-frequency unstable combustion occurs when the initial LOX particle diameter is larger than $60 \mu \mathrm{m}$. And the combustor flow field exhibits other typical characteristics: the streamwise length of spray trajectories is almost unchanged, while the swinging process of spray trajectories in the transverse direction is synchronous with the 


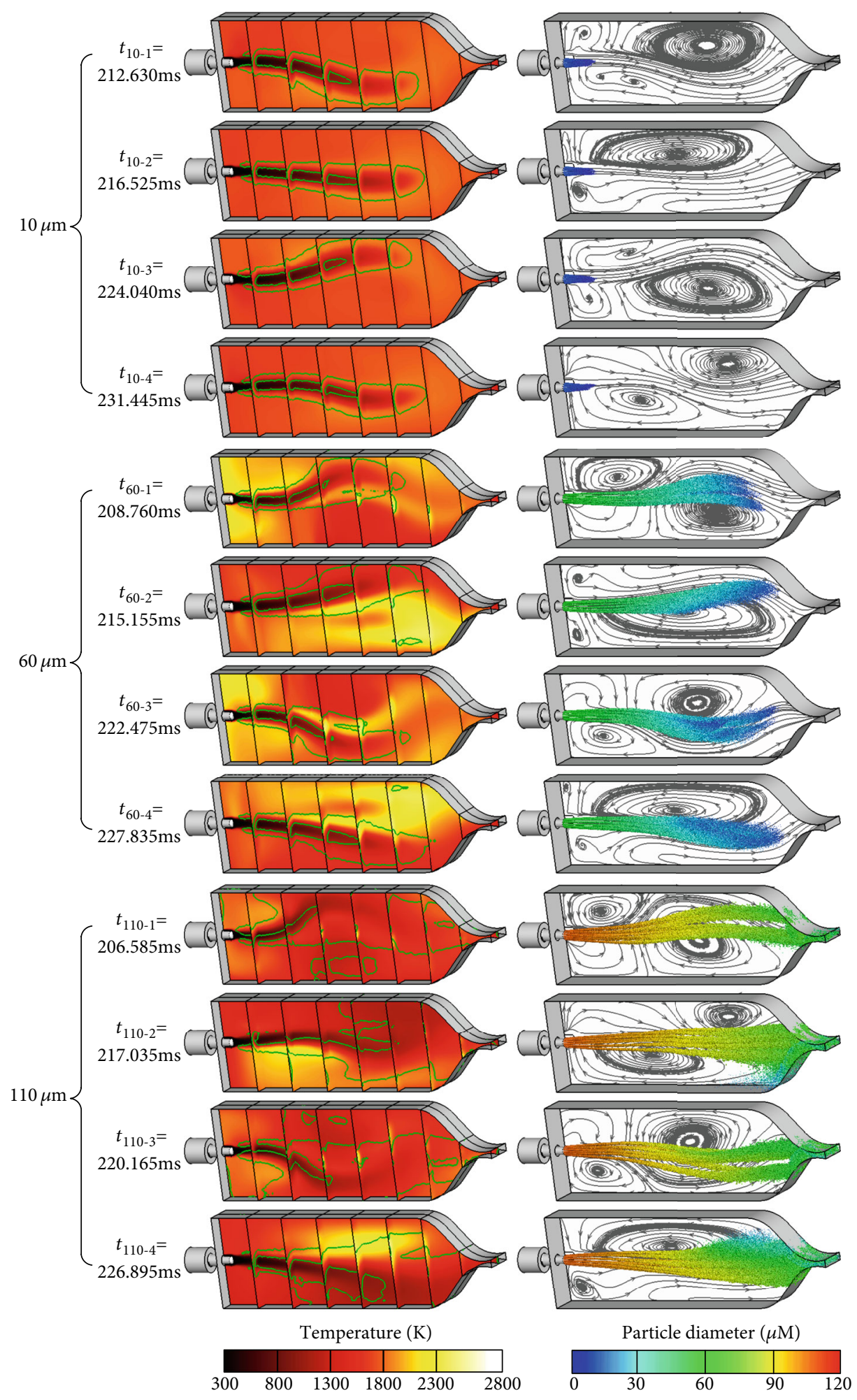

FIGURE 16: Evolution of the combustion flow field for different initial LOX particle diameters in one period of pressure oscillation: the left column shows the cycle snapshots of the temperature distribution and the reaction region surrounded by green lines; the right column shows the streamline in the $z=0$ plane and the distribution of LOX particles; all the time points are marked in Figure 14(a).

combustor pressure oscillation. Besides, with the appearance and disappearance of the local high-temperature region in the combustion chamber, the combustion reaction also enhances or weakens synchronously.
In order to perform a quantitative analysis of the combustor temperature field, the orthogonal decomposition method summarized briefly in the appendix was employed to separate the time and space information for the evolution 


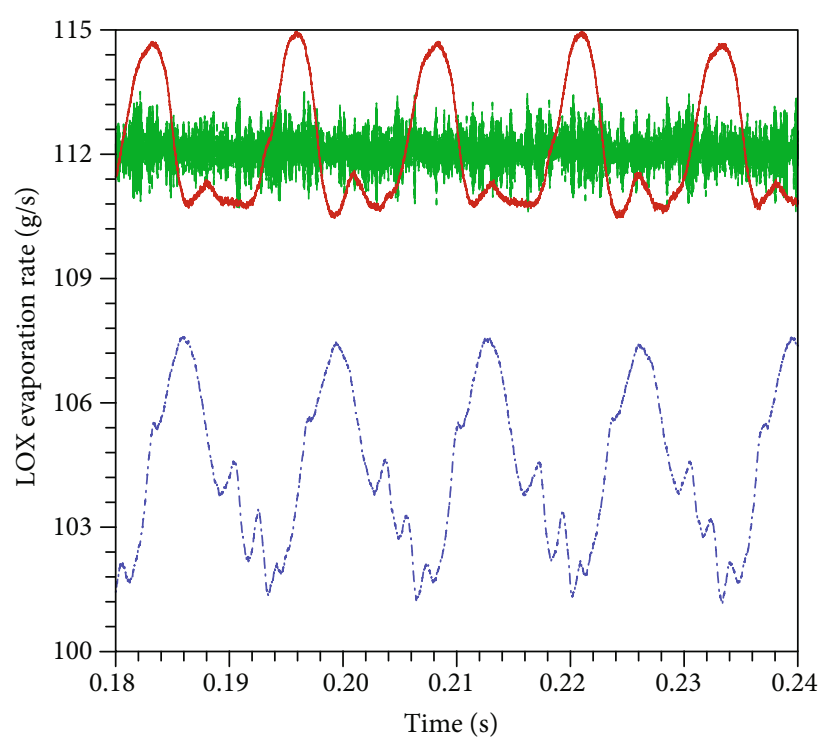

(a)

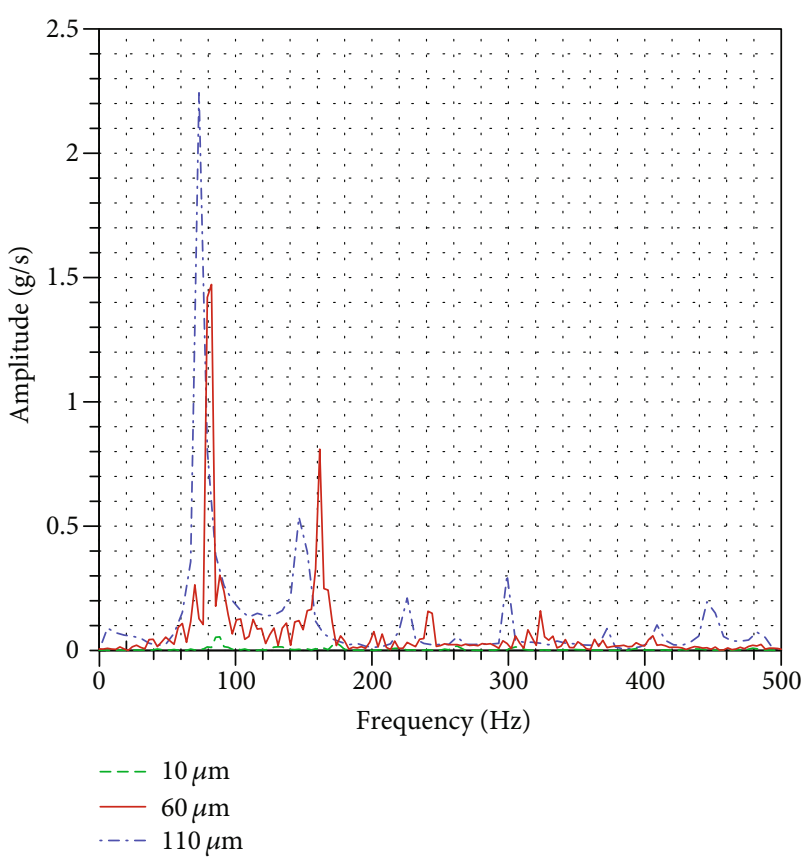

(b)

FIgURE 17: Time histories (a) of the LOX evaporation rate oscillations and the corresponding spectrograms (b) for different initial LOX particle diameters.

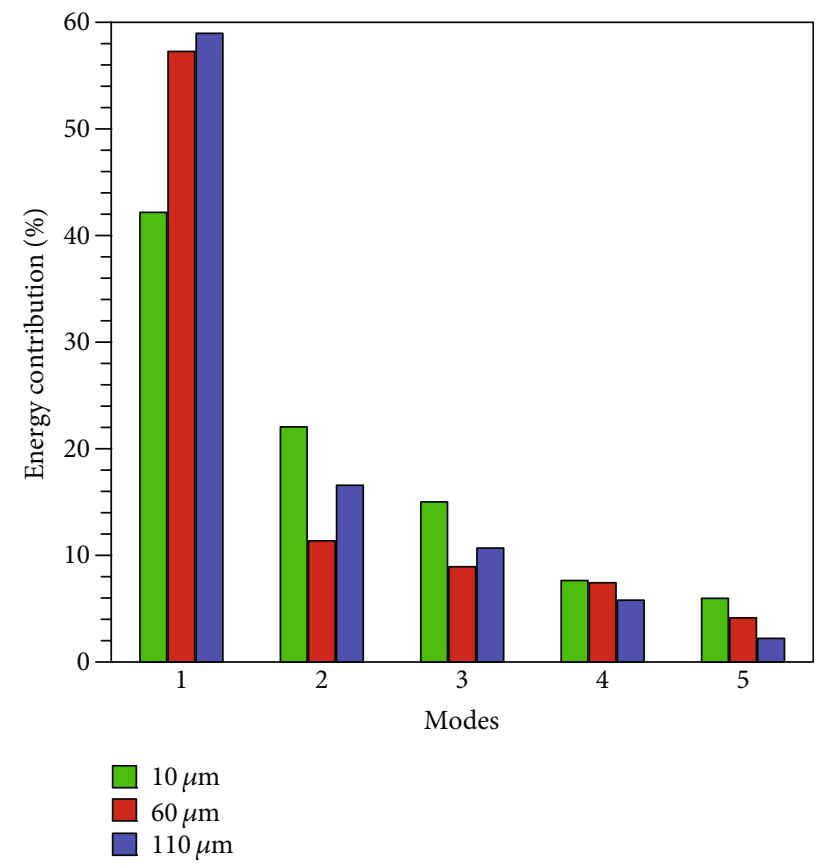

FIGURE 18: Energy contribution of the top five modes for different initial LOX particle diameters.

of the temperature distribution in the $z=0$ plane. According to the energy distribution of the top five modes in Figure 18, mode-1 contributes far more energy than other modes for different initial LOX particle diameters, which indicates that mode-1 dominates the evolution of the temperature distribution in the $z=0$ plane. As shown in Figure 19(a), the spatial structures of mode-1 for different initial LOX particle diameters are symmetrical about the combustor axis, and the signs on both sides are opposite. The scope with larger absolute values is basically consistent with the reaction region in Figure 16, which expands along with the increase of the initial LOX particle diameter. Thus, mode-1 corresponds to the swinging process of the spray and flame in the $y$-direction. The Fourier transform was carried out for the time coefficient of mode-1, and strong peaks at $43 \mathrm{~Hz}$ are observed for different initial LOX particle diameters in Figure 19(b). With reference to Figure 15, it can be seen that the combustor pressure oscillation at $40 \mathrm{~Hz}$ is coupled with the combustion process. Under the effect of pressure difference between the upper and lower walls, the recirculation zone in the relatively high-pressure side continues to increase in size until spanning the entire combustor, while the recirculation zone in the other side is gradually squeezed to the head of the combustor. The spray and flame are also pushed to the relatively low-pressure side by the pressure difference. The enhanced combustion reaction in the relatively low-pressure side causes the increase of the local temperature and pressure, and the reverse change occurs on the other side. Accordingly, the spray and the flame move in the reverse direction with the size change of the recirculation zones near the upper and lower walls. It can be drawn that the reciprocating occurrence of the above process maintains the combustor pressure oscillation at $40 \mathrm{~Hz}$.

\section{Conclusions}

Numerical simulation was performed to study the effect of the initial LOX particle diameter on the combustion 


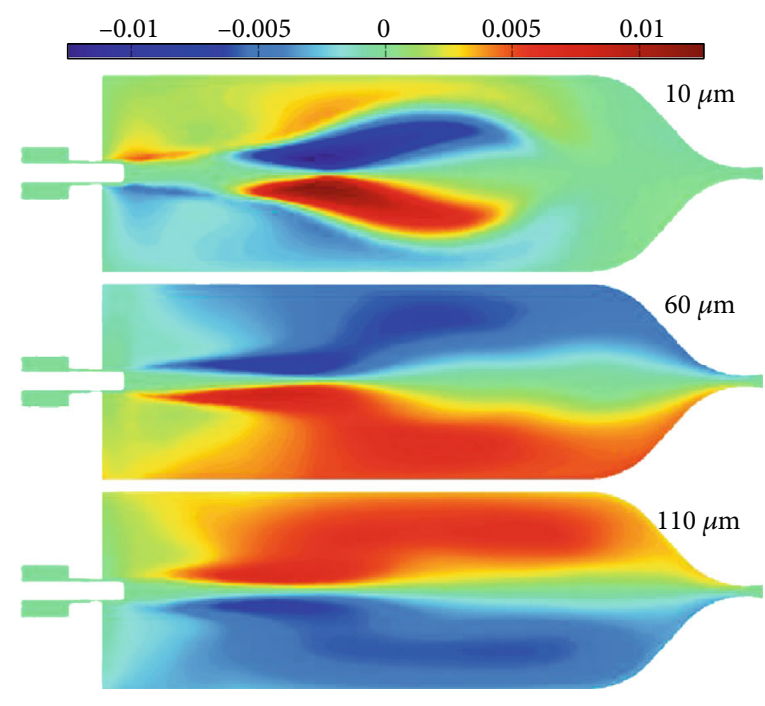

(a)

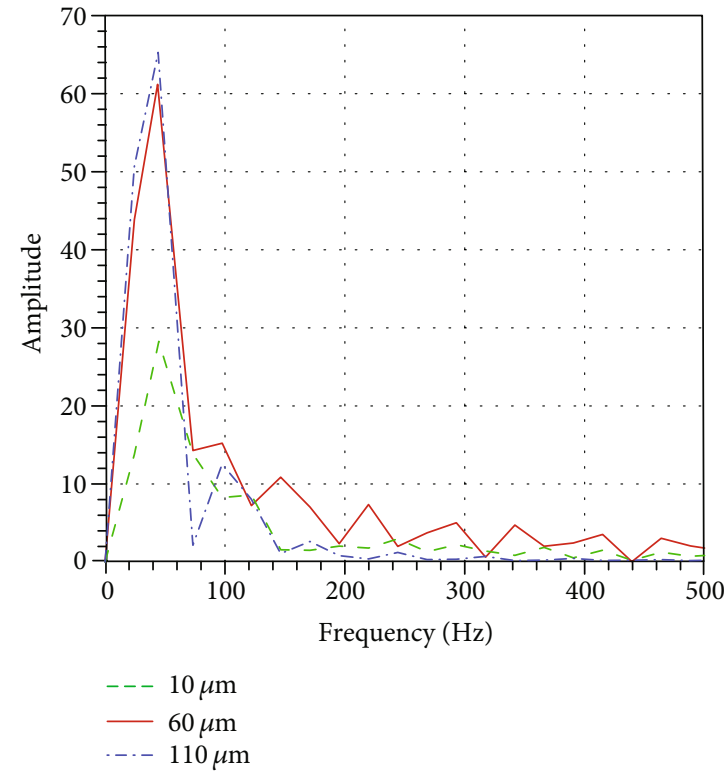

(b)

FIgURE 19: Space structures (a) of mode-1 and the spectrograms (b) of the corresponding time coefficient for different initial LOX particle diameters.

characteristics of a $\mathrm{LOX} / \mathrm{GCH}_{4}$ pintle rocket engine with a rectangular combustion chamber. The fuel is the premixed gas, methane and nitrogen. Numerical results agree well with the designed values, which indicates that the Euler-Lagrange method used in this paper is reasonable. Several conclusions drawn from the numerical analysis are gained:

(1) As the momentum ratio between the radial LOX jet and the axial gas jet is 0.033 , LOX particles with the initial particle diameter of $10 \mu \mathrm{m}$ cannot penetrate the premixed fuel gas after being injected radially into the combustor and are completely evaporated at $x=65 \mathrm{~mm}$. Large recirculation zones are formed in the transverse direction and contribute to the uniform temperature distribution in the combustor. And premixed combustion occurs in the surrounding region of the injector wake. Thus, the combustor flow field differs greatly from the previous research results

(2) As the initial LOX particle diameter increases, the evaporation rate of the LOX particles decreases significantly, while the streamwise length of spray trajectories increases until some droplets leave the engine without evaporating completely. Accordingly, the combustor pressure stays away from the designed value, and the combustion terminates when the initial LOX particle diameter is greater than $110 \mu \mathrm{m}$

(3) The oscillation amplitude of the combustor pressure increases significantly along with the increase of the initial LOX particle diameter, and the lowfrequency unstable combustion occurs when the initial LOX particle diameter exceeds $60 \mu \mathrm{m}$. And the main frequencies of the combustor pressure oscilla- tions are mainly concentrated in the vicinity of $40 \mathrm{~Hz}, 80 \mathrm{~Hz}$, and $160 \mathrm{~Hz}$. The combustor pressure oscillation at about $40 \mathrm{~Hz}$ couples with the swinging process of spray and flame in the transverse direction. The combustion reaction is synchronously enhanced or weakened in the swinging process with a large initial LOX particle diameter, while the streamwise length of spray trajectories remains nearly constant. With the same peaks at about $80 \mathrm{~Hz}$ and its harmonic frequency during the steady stage, it can be concluded that the unsteady LOX evaporation amplifies the combustor pressure oscillations

The combustion efficiency and combustion stability of the $\mathrm{LOX} / \mathrm{GCH}_{4}$ pintle rocket engine can be dramatically improved by decreasing the initial LOX particle diameter. However, the initial LOX particle diameter is closely related to many factors. Subsequent experiments are required to verify the simulation results and further investigate the effects of related parameters, such as the injection orifice dimensions and injection pressure drop, on the combustion characteristics of the $\mathrm{LOX} / \mathrm{GCH}_{4}$ pintle rocket engine.

\section{Appendix}

The dynamic information $\mathbf{U}(\mathbf{R}, t)$ in linear space $\mathbf{R}$ can be decomposed into time and spatial information using the following equation:

$$
\boldsymbol{U}(\boldsymbol{R}, t)=\sum_{n=1}^{N} f_{n}(t) \cdot \Phi_{n}(\boldsymbol{R}),
$$

where $\Phi=\left[\Phi_{1} \cdots \Phi_{n} \cdots \Phi_{N}\right]$ is a set of maximum independent vectors in linear space $\mathbf{R}$, i.e., a set of basis in $\mathbf{R}$ space; 
$\Phi_{n}$ is a mode of $\mathbf{U}(\mathbf{R}, t)$ which includes spatial information; $F=\left[f_{1} \cdots f_{n} \cdots f_{N}\right]$ is the projection of $\mathbf{U}(\mathbf{R}, t)$ on the vector $\boldsymbol{\Phi}$, i.e., a linear expression relative to the set of basis in $\mathbf{R}$ space; $f_{\mathrm{n}}(t)$ is the time coefficient of $\Phi_{n}$ and represents the projection of $\mathbf{U}(\mathbf{R}, t)$ on the vector $\Phi_{\mathrm{n}}$ at time $t$.

It can be assumed that a set of time-discrete data $\mathbf{U}$ obtained in the unsteady simulations contains the data, $U_{1}(\mathbf{R}), U_{2}(\mathbf{R}) \cdots U_{K}(\mathbf{R})$, which corresponds to discrete time points, $t_{1}, t_{2} \cdots t_{K}$. The time-discrete data $U$ can be decomposed as

$$
\boldsymbol{U}^{*}=\Phi \cdot F^{\mathrm{T}}=\left[\begin{array}{llll}
\Phi_{1} & \Phi_{2} \cdots \Phi_{K}
\end{array}\right] \cdot\left[\begin{array}{llll}
f_{1} & f_{2} \cdots f_{K}
\end{array}\right]^{\mathrm{T}} .
$$

The error $E$ between the original data $\mathbf{U}$ and the reconstructed information $\mathbf{U}^{*}$ is

$$
E=\left\|\boldsymbol{U}-\boldsymbol{U}^{*}\right\|
$$

Based on the idea of orthogonal decomposition, no two vectors in a set of basis in $\mathbf{R}$ space are linearly independent. In order to obtain the set of basis that minimizes the error $E$, the solution is as follows:

(1) Solve the eigenvalue problem of the self-covariance matrix $\mathbf{C}=\mathbf{U}^{\mathrm{T}} \mathbf{U}$ :

$$
C \cdot A_{k}=A_{k} \cdot \lambda_{k}
$$

(2) Export the mode $\Phi_{k}$ corresponding to the eigenvalue $\lambda_{k}$ through Equation (A.5):

$$
\Phi_{k}=\frac{U \cdot A_{k}}{\left\|U \cdot A_{k}\right\|}
$$

(3) Calculate the time coefficients of all modes using the following equation:

$$
F=\left[\begin{array}{llll}
\Phi_{1} & \Phi_{2} & \cdots & \Phi_{K}
\end{array}\right]^{\mathrm{T}} \cdot \boldsymbol{U}
$$

(4) The magnitude of the eigenvalue $\lambda_{k}$ reflects the energy contribution of the corresponding mode $\Phi_{k}$. All the modes $\left[\Phi_{1} \cdots \Phi_{n} \cdots \Phi_{K}\right]$ and their time coefficient $\left[f_{1} \cdots f_{n} \cdots f_{K}\right]$ are rearranged in the order of eigenvalues from large to small $\lambda_{1}>\lambda_{2}>\cdots>\lambda_{k}$

\section{Nomenclature}

$$
\begin{array}{ll}
A_{\mathrm{t}}: & \text { Throat area } \\
\mathrm{BF}: & \text { Blocking factor } \\
c_{\mathrm{th}}{ }^{*}: & \text { Theoretical characteristic velocity }
\end{array}
$$

$c^{*}: \quad$ Characteristic velocity

$D_{0.1}: \quad 10 \%$ volume undersize diameters

$D_{0.9}: \quad 90 \%$ volume undersize diameters

$D_{\mathrm{m}}$ : Diffusion coefficient of species $\mathrm{m}$

DPM: Discrete phase model

$D_{\mathrm{p}}$ : $\quad$ Pintle diameter

$D_{\mathrm{SMD}}$ : Sauter average diameter

$d$ : Injection orifice diameter

E: Total energy

EDC: Eddy dissipation concept model

$F_{\mathrm{s}, \mathrm{i}}: \quad$ Interphase exchange terms

$h$ : Axial injection channel width

JL: Jones-Lindstedt 4-step mechanism

$L_{\mathrm{s}}: \quad$ Skip distance

$N$ : Injection orifice number

$P^{\prime}$ : $\quad$ Pressure oscillation amplitude

$p: \quad$ Pressure

$p_{c}: \quad$ Combustor pressure

$Q_{s}: \quad$ Interphase exchange terms

$q_{i}: \quad$ Heat flux in $i$-direction

$q_{\mathrm{m}}: \quad$ Mass flow rate

$\mathrm{Sc}_{\mathrm{t}}$ : Schmitt number

$S_{\mathrm{h}}$ : $\quad$ Source terms due to chemical reaction

$S_{\mathrm{s}, \mathrm{m}}$ : Interphase exchange terms

$T_{c}$ : Combustor temperature

TMR: Total momentum ratio

$t$ : Physical time

$\Delta t: \quad$ Time step

$u$ : Characteristic flow velocity

$u$ : Velocity in $i$-direction

$\Delta x: \quad$ Local grid size

$Y_{\mathrm{m}}: \quad$ Mass fraction of species $\mathrm{m}$

$\eta_{\mathrm{c}}{ }^{*}$ : $\quad$ characteristic exhaust velocity efficiency

$\mu_{\mathrm{t}}: \quad$ Turbulent viscosity coefficient

$\rho: \quad$ Density

$\rho_{\mathrm{s}}: \quad$ Interphase exchange terms

$\tau_{\mathrm{ij}}: \quad$ Viscous stress

$\omega_{\mathrm{m}}$ : Source terms due to chemical reaction.

\section{Data Availability}

The data used to support the findings of this study are included within the article.

\section{Conflicts of Interest}

The authors declare no conflict of interest.

\section{Acknowledgments}

This work was supported by the National Natural Science Foundation of China (11572346) and Natural Science Foundation of Hunan Province, China (2020JJ4666).

\section{References}

[1] Q. D. Han, X. Hong, and H. Q. Zhou, “Analysis on requirment and development of space propulsion technology," Journal of Rocket Propulsion, vol. 38, no. 2, pp. 9-15, 2012. 
[2] Y. L. Pan, H. Q. Zhou, L. Ji, and H. B. Xu, "Study on ignition technology of LOX/LCH4 attitude control," Journal of Rocket Propulsion, vol. 45, no. 4, pp. 16-25, 2019.

[3] H. M. Sun, "Review of liquid oxygen/methane rocket engine," Journal of Rocket Propulsion, vol. 32, no. 2, pp. 23-31, 2006.

[4] B. Li, X. P. Zhang, and Y. S. Gao, "Consideration on development of reusable liquid rocket engine in China," Journal of Rocket Propulsion, vol. 43, no. 1, pp. 1-7, 2017.

[5] S. Y. Huang, J. Zhou, S. J. Liu, and H. Y. Peng, "Effects of pintle injector on ethylene-air rocket-based continuous rotating detonation," Acta Astronautica, vol. 164, pp. 311-320, 2019.

[6] L. Yuan, Study on self-sustained mechanism of high frequency combustion instability in air heater, Ph. D. Dissertation, National University of Defense Technology, Changsha, 2018.

[7] P. Cheng, The dynamics of spray combustion in variable thrust ricket engines, $\mathrm{Ph}$. D. Dissertation, National University of Defense Technology, Changsha, 2018.

[8] P. An, S. Q. Yao, J. L. Wang, and W. L. Zhou, "Characteristics and design of pintle injector," Missiles and Space Vehicles, vol. 345, no. 3, pp. 50-54, 2016.

[9] G. A. Dressler, "Summary of deep throttling rocket engines with emphasis on Apollo LMDE," in 42nd AIAA/ASME/SAE/ASEE Joint Propulsion Conference \& Exhibit, Sacramento, California, July 2006.

[10] J. Lei, X. Lan, R. Zhang, and W. Chen, "The development of $7500 \mathrm{~N}$ variable thrust engine for Chang'e-3," Scientia Sinica Technologica, vol. 44, no. 6, pp. 569-575, 2014.

[11] Z. Z. Sun, H. Jia, and H. Zhang, "Technological advancements and promotion roles of Chang'e-3 lunar probe mission," Scientia Sinica Technologica, vol. 56, no. 11, pp. 2702-2708, 2013.

[12] L. A. Davis, "First stage recovery," Engineering, vol. 2, no. 2, pp. 152-153, 2016.

[13] E. Seedhouse, SpaceX: making commercial spaceflight a reality, Praxis Press, Chichester, UK, 2013.

[14] G. A. Dressler and J. M. Bauer, "TRW pintle engine heritage and performance characteristics," in 36th AIAA/ASME/SAE/ASEE Joint Propulsion Conference \& Exhibit, Huntsville, Alabama, July 2000.

[15] S. D. Heister, Handbook of Atomization and Aprays: Theory and Applications, Springer Science +Business Media, New York, USA, 2011.

[16] M. Son, K. Yu, J. Koo, O. C. Kwon, and J. S. Kim, "Effects of momentum ratio and Weber number on spray half angles of liquid controlled pintle injector," Journal of Thermal Science, vol. 24, no. 1, pp. 37-43, 2015.

[17] M. Son, K. Yu, K. Radhakrishnan, B. Shin, and J. Koo, "Verification on spray simulation of a pintle injector for liquid rocket engine," Journal of Thermal Science, vol. 25, no. 1, pp. 90-96, 2016.

[18] M. Son, K. Radhakrishnan, J. Koo, O. C. Kwon, and H. D. Kim, "Design procedure of a movable pintle injector for liquid rocket engines," Journal of Propulsion and Power, vol. 33, no. 4, pp. 858-869, 2017.

[19] S. Lee, D. Kim, J. Koo, and Y. Yoon, "Spray characteristics of a pintle injector based on annular orifice area," Acta Astronautica, vol. 167, pp. 201-211, 2020.

[20] Y. Zhang, N. Yu, H. Tian, W. Li, and H. Feng, "Experimental and numerical investigations on flow field characteristics of pintle injector," Aerospace Science and Technology, vol. 103, pp. 1-9, 2020.
[21] K. Sakaki, T. Funahashi, S. Nakaya et al., "Longitudinal combustion instability of a pintle injector for a liquid rocket engine combustor," Combustion and Flame, vol. 194, pp. 115-127, 2018.

[22] K. Sakaki, H. Kakudo, S. Nakaya et al., "Combustion characteristics of ethanol/liquid-oxygen rocket-engine combustor with planar pintle injector," Journal of Propulsion and Power, vol. 33, no. 2, pp. 514-521, 2017.

[23] K. Sakaki, H. Kakudo, S. Nakaya et al., "Performance evaluation of rocket engine combustors using ethanol/liquid oxygen pintle injector," in 52nd AIAA/SAE/ASEE Joint Propulsion Conference, Salt Lake City, UT, July 2016.

[24] K. Sakaki, H. Kakudo, S. Nakaya et al., "Optical measurements of ethanol/liquid oxygen rocket engine combustor with planar pintle injector," in 51st AIAA/SAE/ASEE Joint Propulsion Conference, Orlando, FL, July 2015.

[25] P. Cheng, Q. L. Li, and H. Y. Chen, "Flow characteristics of a pintle injector element," Acta Astronautica, vol. 154, pp. 6166, 2019.

[26] P. Cheng, Q. Li, S. Xu, and Z. Kang, "On the prediction of spray angle of liquid-liquid pintle injectors," Acta Astronautica, vol. 138, pp. 145-151, 2017.

[27] H. Y. Chen, Q. L. Li, and P. Cheng, "Experimental research on the spray characteristics of pintle injector," Acta Astronautica, vol. 162, pp. 424-435, 2019.

[28] H. Y. Chen, Q. L. Li, P. Cheng, W. H. Lin, and C. Y. Li, "Influence of momentum ratio and its throttling method on spray characteristics of pintle injector," Acta Physica Sinica, vol. 68, no. 20, pp. 204704-204717, 2019.

[29] X. X. Fang and C. B. Shen, "Study on atomization and combustion characteristics of LOX/methane pintle injectors," Acta Astronautica, vol. 136, pp. 369-379, 2017.

[30] H. Asakawa, H. Nanri, I. Masuda, R. Shinohara, Y. Ishikawa, and H. Sakaguchi, "Study on combustion characteristics of LOX/LNG (methane) coaxial type injector under high pressure condition," in 52nd AIAA/SAE/ASEE Joint Propulsion Conference, Salt Lake City, UT, July 2016.

[31] J. Lux and O. Haidn, "Effect of recess in high-pressure liquid oxygen/methane coaxial injection and combustion," Journal of Propulsion and Power, vol. 25, no. 1, pp. 24-32, 2009.

[32] T. Yang, D. Q. Fang, and Q. G. Tang, Combustion Principle of Rocket Engine, National University of Defense Technology Press, Changsha, China, 2008.

[33] Z. G. Wang, Modeling and Numerical Simulations of Intenal Combustion Process of Liquid Rocket Engines, National Defense Industry Press, Beijing, China, 2012.

[34] Y. S. Chen, T. H. Chou, B. R. Gu et al., "Multiphysics simulations of rocket engine combustion," Computer \& Fluids, vol. 45, no. 1, pp. 29-36, 2011.

[35] ANSYS. Inc, “ANSYS fluent guide," http://www.ansys.com (accessed on July 2015).

[36] M. G. Giorgi, A. Sciolti, and A. Ficarella, "Application and comparison of different combustion models of high pressure LOX/CH4 jet flames," Energies, vol. 7, no. 1, pp. 477-497, 2014.

[37] J. Andersen, C. L. Rasmussen, T. Giselsson, and P. Glarborg, "Global combustion mechanisms for use in CFD modeling under oxy-fuel conditions," Energy \& Fuels, vol. 23, no. 3, pp. 1379-1389, 2009.

[38] M. Rachner, M. Brandt, H. Eickhoff et al., "A numerical and experimental study of fuel evaporation and mixing for lean 
premixed combustion at high pressure," Symposium (International) on Combustion, vol. 26, no. 2, pp. 2741-2748, 1996.

[39] M. Son, K. Radhakrishnan, Y. Yoon, and J. Koo, "Numerical study on the combustion characteristics of a fuel-centered pintle injector for methane rocket engines," Acta Astronautica, vol. 135, pp. 139-149, 2017.

[40] E. Schreck and M. Schäfer, "Numerical study of bifurcation in three-dimensional sudden channel expansions," Computers \& Fluids, vol. 29, no. 5, pp. 583-593, 2000.

[41] N. Moallemi and J. R. Brinkerhoff, "Numerical analysis of laminar and transitional flow in a planar sudden expansion," Computers \& Fluids, vol. 140, pp. 209-221, 2016.

[42] S. Gordon and B. J. McBride, Computer program for calculation of complex chemical equilibrium compositions and applications, NASA Langley Research Center, Cleveland, Ohio, 1994.

[43] K. D. Huzel and H. D. Huang, Modern engineering for design of liquid-propellant rocket engines, AIAA, Washington DC, USA, 1992.

[44] F. E. C. Culick, Unsteady motions in combustion chambers for propulsion systems, AGARD \& RTO, Virginia, USA, 2006.

[45] H. Tamura, H. Sakamoto, M. Takahashi, M. Sasaki, and T. Onodera, "Observation of LOX/hydrogen combustion flame in a rocket chamber during chugging instability," in 39th AIAA/ASME/SAE/ASEE Joint Propulsion Conference and Exhibit, Huntsville, Alabama, July 2003. 